\title{
Seismic Behaviour of Cast-In-Situ Phosphogypsum-Reinforced Concrete Grid Frame Composite Walls
}

\author{
Qin Wu, ${ }^{1,2}$ Huagang Zhang $\mathbb{D}^{1,2}$ Hongniao Chen, ${ }^{1,2}$ Xin Zhang, ${ }^{1,2}$ YanHui Wei, ${ }^{1,2}$ Li Li, $^{3}$ \\ and Kejian $\mathrm{Ma}^{1,2}$ \\ ${ }^{1}$ Space Structures Research Center, Guizhou University, Guiyang GZ 851, China \\ ${ }^{2}$ Guizhou Key Laboratory of Structural Engineering, Guiyang GZ 851, China \\ ${ }^{3}$ Collage of Civil Engineering, Guizhou University, Guiyang GZ 851, China
}

Correspondence should be addressed to Huagang Zhang; hgzhang@gzu.edu.cn

Received 24 July 2019; Accepted 3 October 2019; Published 4 November 2019

Academic Editor: Antonio Formisano

Copyright (c) 2019 Qin Wu et al. This is an open access article distributed under the Creative Commons Attribution License, which permits unrestricted use, distribution, and reproduction in any medium, provided the original work is properly cited.

This paper mainly studies the effect of cast-in-situ phosphogypsum on seismic behaviour of reinforced concrete grid frame. The mechanical behaviour of three reinforced concrete grid frames and four cast-in-situ phosphogypsum-reinforced concrete grid frame composite walls under low cycle alternating load was designed and tested. The test results show that the reinforced concrete grid frame has less bearing capacity and poor energy consumption. The addition of cast-in-situ phosphogypsum can effectively improve the seismic behaviour of the reinforced concrete grid frame. Compared with the reinforced concrete grid frame, the bearing capacity of the cast-in-situ phosphogypsum-reinforced concrete grid frame composite wall is increased by 2-3 times, the displacement ductility coefficient is increased by $0.95 \sim 1.2$ times, and the relative accumulative energy consumption is increased by 86\% 216\%. This shows that the composite wall has better bearing capacity, ductility, and energy dissipation capacity.

\section{Introduction}

Phosphogypsum is a solid waste discharged from the production of phosphoric acid by wet process. Being rich in $\mathrm{P}_{2} \mathrm{O}_{5}$ and fluorides, the dissolution and leakage of this harmful substance during storage cause serious environmental pollution [1]. In China, the accumulative stock of phosphogypsum has reached 300 million tons [2]. Therefore, its pollution should be comprehensively controlled. The provincial government of Guizhou is rich in phosphogypsum resources. Starting in 2018, the government requires phosphorous chemical enterprises to digest not only the phosphogypsum discharged in the current year but also their historical stock year by year.

At present, the utilisation of phosphogypsum mainly focuses on the following aspects [3]:

(i) Most of techniques used in the chemical industry require phosphogypsum before treatment, which comes with high investment, high energy consumption, and new emissions. (ii) Industrial waste phosphogypsum is used as a lime stabilizer for expansive soil to stabilize the soil [4].

(iii) Phosphogypsum and phosphorus slag were used as cementitious materials for cemented paste backfill body to treat goafs in mines [5], but it is unsuitable for open-cast mines.

(iv) Building materials are mainly used for the production of cement retarder [6] and sulfuric acid combined with cement and decoration materials and blocks [7]. These products have low radioactively detection indices [8].

(v) In terms of roadbed materials, phosphogypsum is mainly used as a stabilizer [9] and solidifier [10] to treat sludge, so as to meet the requirements of roadbed materials.

All of these approaches to phosphogypsum have shortcomings. Therefore, it is necessary to find ways to use phosphogypsum directly. 
Based on the characteristics of fast setting time of phosphogypsum (only 3-5 minutes), Ma et al. [11] proposed the idea of pouring phosphogypsum in building, but the fluidity of phosphogypsum slurry is poor, and the free water evaporates slowly after hardening. After hydration of the phosphogypsum provided by WengFu group co. Ltd., Cao et al. [12] observed by JMS-6490LV scanning electron microscope and found that phosphogypsum crystals were parallel-shaped (Figure 1, ruler $100 \mu \mathrm{m}$ ). The gypsum phase composition was analysed by D5000 XRD diffractometer. It was found that gypsum contained not only $\beta-\mathrm{CaSO}_{4} \cdot 0.5 \mathrm{H}_{2} \mathrm{O}$ but also a small amount of $\mathrm{CaSO}_{4}$ and $\mathrm{SiO}_{2}$ (Figure 2). Therefore, the interspaces between phosphogypsum crystals can be filled with compatible phosphorus slag powder (Figures 3 and 4), and $\mathrm{Ca}_{4} \mathrm{Al}_{6} \mathrm{SO}_{16}$ after cement hydration can consume $\mathrm{CaSO}_{4}$. The acidity of phosphogypsum can be integrated with $\mathrm{CaO}$, which can reduce the solubility and dissolution rate of $\beta$ - $\mathrm{CaSO}_{4} \cdot 0.5 \mathrm{H}_{2} \mathrm{O}$, and extend the setting time of phosphogypsum by retarder. The reduction of free water can be achieved by water reducing agent. It is proposed that the quality ratio of raw materials is as follows: $80 \%$ phosphogypsum, $17 \%$ phosphorus slag powder, $3 \%$ $\mathrm{CaO}, 2 \%$ cement, $0.8 \%$ water reducer, $0.22 \%-0.35 \%$ retarder, and $0.43-0.46$ water-to-cement ratio, which effectively solves the aforementioned problems.

On this basis, Wu et al. [13] measured the uniaxial stressstrain curve of phosphogypsum through prismatic specimens and revealed that the elastic modulus of the material was $5300 \mathrm{MPa}$ and Poisson's ratio was 0.19. Zhang et al. [14] measured the compressive strength of phosphogypsum at 9.6 MPa-10.4 MPa and the partial factor for materials at 1.9 through cube specimens and conducted engineering practice in two rural residences in ZunYi, Guizhou province (Figure 5).

Using phosphogypsum as the filling material of the structure, Ma et al. [15] proposed the cast-in-situ phosphogypsum-reinforced concrete composite box structure. The floor slab adopted the box-shaped floor with precast phosphogypsum mould box, and the load-bearing wall was the cast-in-situ phosphogypsum-reinforced concrete mesh frame composite wall. The stability analysis conducted by Zhang et al. $[16,17]$ shows that the composite wall has sufficient elastic and stable bearing capacity, and the engineering practice of high-rise housing shown in Figure 6 is carried out in Machangping, Guizhou province. The ratio of concrete and phosphogypsum in the structure is $1: 0.71$, which indicates that a large number of applications of phosphogypsum can be realized in the building structure.

According to this project, the construction technology of cast-in-situ phosphogypsum-reinforced concrete grid frame composite wall can be summarized as follows. (1) Check the reinforced concrete grid frame and repair construction defects (Figure 7(a)). (2) Install the template of cast-in-situ phosphogypsum on both sides of the reinforced concrete grid frame, and seal the gap between the templates by sealing strips (Figure 7(b)). (3) Weigh dry materials such as phosphogypsum, phosphorous slag powder, lime, and cement according to the mass mixing ratio. After mixing uniformly, pour into the aqueous solution prepared by water

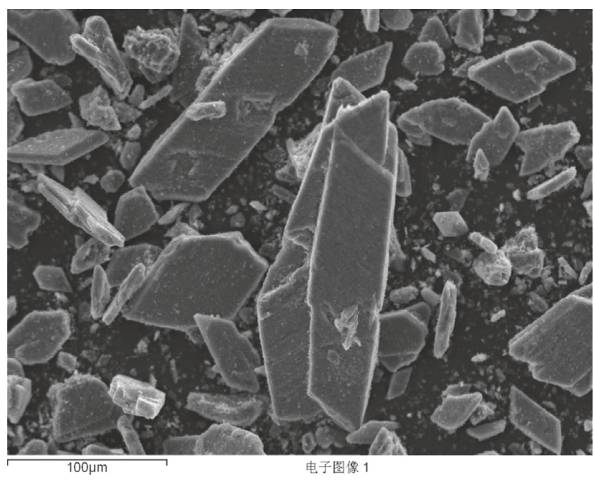

FIgURE 1: SEM photo of phosphogypsum (ruler $100 \mu \mathrm{m}$ ).

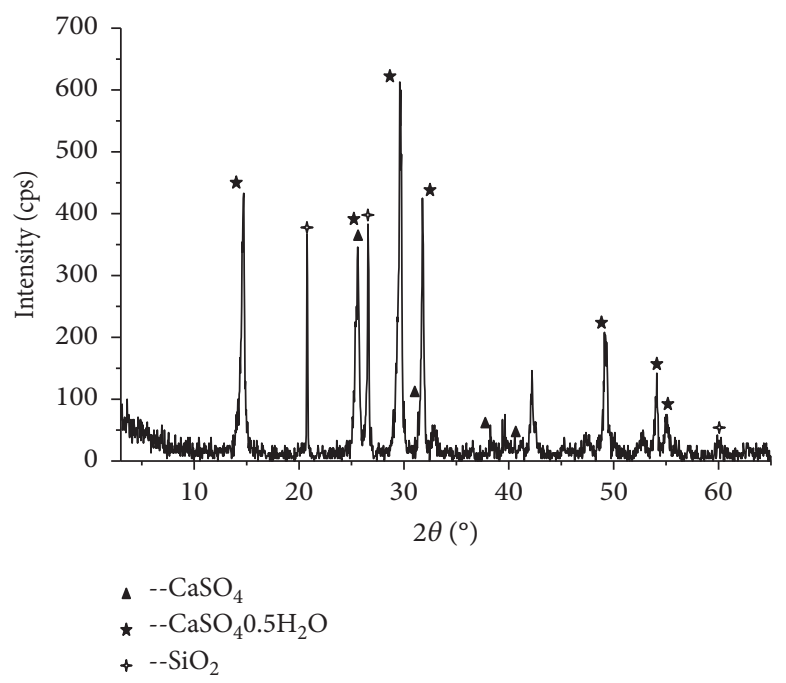

FIGURE 2: XRD pattern of phosphogypsum.

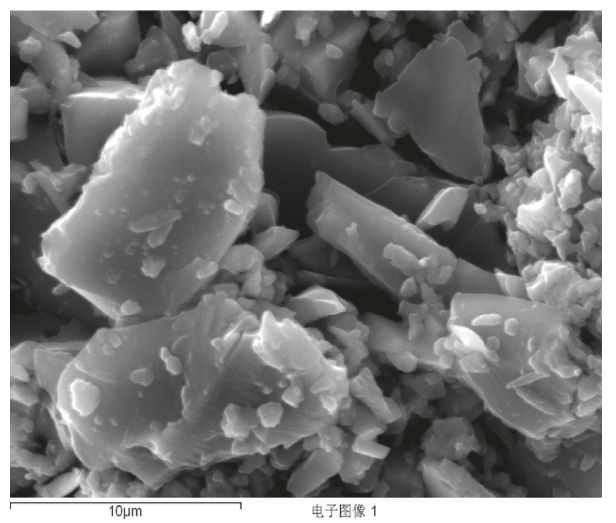

Figure 3: SEM photo of phosphorus slag powder (ruler $10 \mu \mathrm{m}$ ).

reducer and retarder, and stir again to obtain the pouring slurry of phosphogypsum (Figure 7(c)). (4) Pumping the slurry into the template, the slurry is self-levelling and basically coagulates in about 30 minutes (Figure 7(d)). (5) Remove the template after about 12 hours (Figure 7(e)).

The microexpansibility of the cast-in-situ phosphogypsum is closely combined with reinforced concrete grid frame and mutually constrained. After the cracking of 


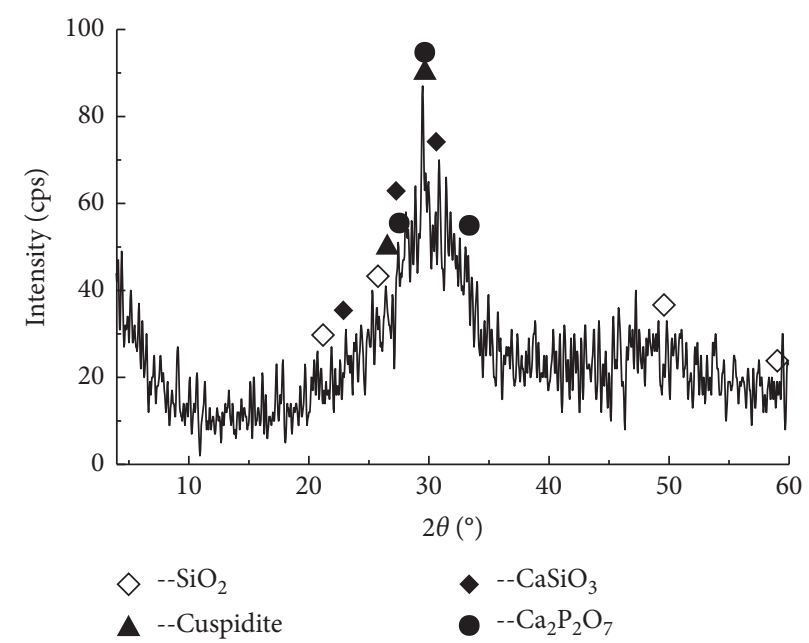

FIGURE 4: XRD pattern of phosphorus slag powder.

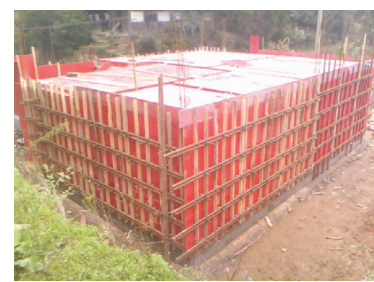

(a)

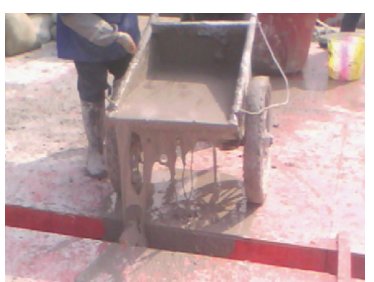

(b)

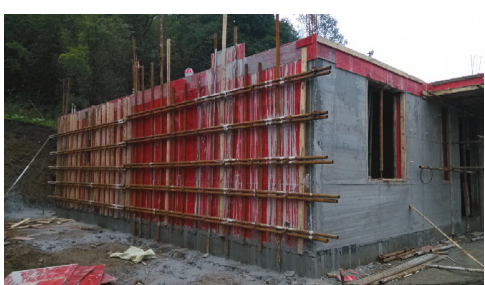

(c)

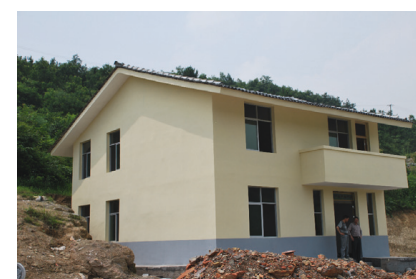

(d)

Figure 5: Cast-in-situ phosphogypsum residential project example. (a) Formwork. (b) Pouring. (c) Form stripping. (d) Building.

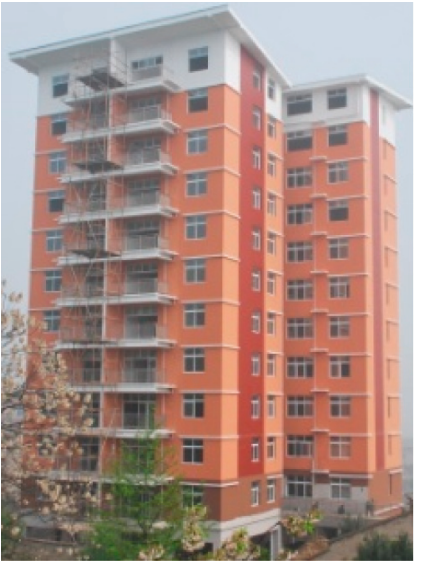

(a)

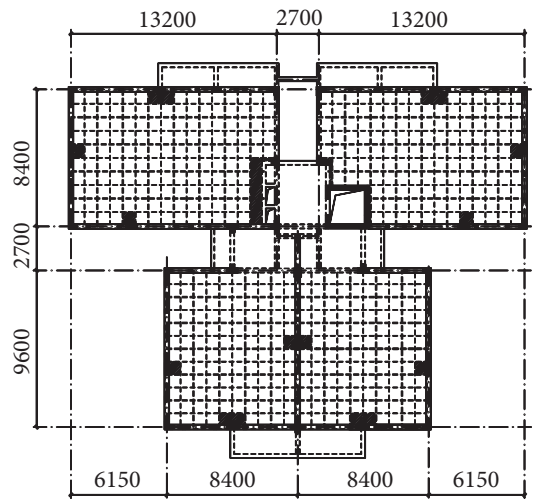

(b)

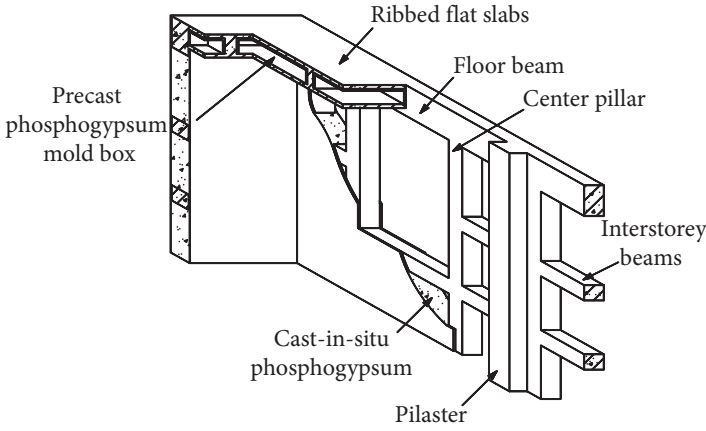

(c)

Figure 6: Guizhou Machangping high-rise housing. (a) Building elevation. (b) Structural plan. (c) Structural space diagram.

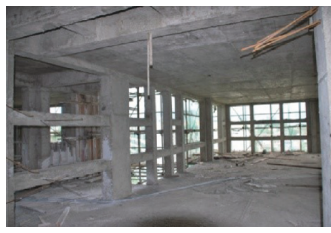

(a)

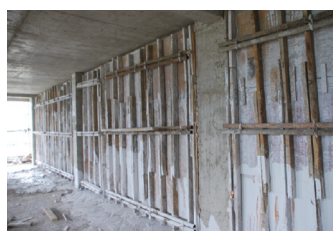

(b)

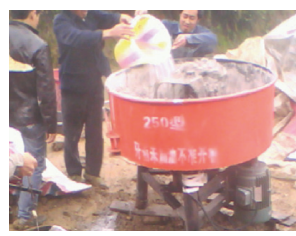

(c)

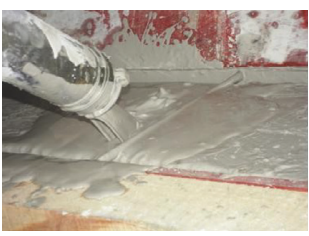

(d)

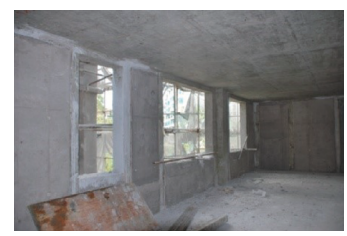

(e)

FIgURE 7: Construction technology of composite wall. (a) Reinforced concrete grid frame. (b) Template installation. (c) Slurry preparation. (d) Phosphogypsum castings. (e) Form stripping. 
phosphogypsum, then the grid frame becomes the main load-bearing framework of the structure [15]. Therefore, cast-in-situ phosphogypsum is the first line of defense against the seismic fortification of structures, and the contribution of its bearing capacity and stiffness in the structure can be considered. However, Lu et al. [18] did not take this effect into account in the study, and the phosphogypsum covered the reinforced concrete grid frame, which is not convenient for the appearance inspection of the grid frame. Jiang et al. $[19,20]$ proposed closely spaced concrete frame-fibre gypsum board composite wall structure, which is connected with closely spaced columns by setting beams at the height of stories. The structure is similar to the shear wall with vertical joints, and the failure is due to bending failure. The setting of interstorey beams in the skeleton significantly changes the mechanical properties of the composite walls.

Modern buildings are mainly high-rise buildings. Based on the above engineering practice and analysis, in order to understand the seismic capacity of cast-in-situ phosphogypsum-reinforced concrete grid frame composite wall, it is necessary to conduct a comparative test study on the composite wall with pure reinforced concrete grid frame under the action of low cyclic alternating load. In this paper, the seismic performance of reinforced concrete grid frame and cast-in-situ phosphogypsum-reinforced concrete grid frame composite wall is compared and tested to understand the structural failure characteristics, bearing capacity, hysteretic curve, skeleton curve, ductility, stiffness, energy dissipation, and other seismic performances.

\section{Materials and Methods}

\subsection{Materials and Mechanical Properties}

2.1.1. Cast-In-Situ Phosphogypsum. Phosphogypsum and phosphorus slag powder were obtained from Weng $\mathrm{Fu}$ group co. Ltd. The gypsum phase of phosphogypsum was determined, as shown in Table 1. The specific surface area of phosphorus slag powder was $380-420 \mathrm{~m}^{2} / \mathrm{kg}$, and chemical composition is shown in Table 2. Hydrated lime was bought in the market, and the effective mass fraction of $\mathrm{CaO}$ was not lower than $60 \%$. The cement used in this study was P.O. 325 ordinary Portland cement. The water reducer was polycarboxylic acid water reducing agent with a concentration of not less than $10 \%$. The retarder used was citrate sodium.

The analysis of Zhang et al. [14] shows that the effect of retarder on the compressive strength of cast-in-situ phosphogypsum is great. Therefore, the mix proportion of castin-situ phosphogypsum is as follows: $80 \%$ phosphogypsum, $17 \%$ phosphorus slag powder, $3 \%$ hydrated lime, $10 \%$ cement, $0.6 \%$ water reducer, and $0.3 \%$ retarder. The water-tocement ratio was 0.43 . The standard value of the cubic compressive strength of cast-in-situ phosphogypsum was 4.2 MPa, and the modulus of elasticity was $2000 \mathrm{~N} / \mathrm{mm}^{2}$.

2.1.2. Steel Bar and Concrete. The concrete used in this study was C20 [21]. The standard value of cubic compressive strength was $20.1 \mathrm{MPa}$. The modulus of elasticity was
TABLE 1: Gypsum compositions of phosphogypsum.

\begin{tabular}{lccc}
\hline $\begin{array}{l}\text { Dihydrate } \\
\text { gypsum (\%) }\end{array}$ & $\begin{array}{c}\beta \text {-hemihydrate } \\
\text { gypsum (\%) }\end{array}$ & Solubility & $\begin{array}{r}\text { Anhydrite (\%) } \\
\text { capacitive }\end{array}$ \\
\hline 0.78 & 87.61 & 2.45 & 2.12 \\
\hline
\end{tabular}

TABLe 2: Chemical compositions of phosphorite slag (\%).

\begin{tabular}{ccccccc}
\hline $\mathrm{SiO}_{2}$ & $\mathrm{Fe}_{2} \mathrm{O}_{3}$ & $\mathrm{Al}_{2} \mathrm{O}_{3}$ & $\mathrm{CaO}$ & $\mathrm{MgO}$ & $\mathrm{P}_{2} \mathrm{O}_{5}$ & $\mathrm{CaF}_{2}$ \\
\hline 42.35 & 1.67 & 3.52 & 45.36 & 1.73 & 1.46 & 1.07 \\
\hline
\end{tabular}

TABLE 3: Mechanical properties of steel bar.

\begin{tabular}{lcccc}
\hline Model & $d(\mathrm{~mm})$ & $f_{y}(\mathrm{MPa})$ & $f_{u}(\mathrm{MPa})$ & $E_{s}(\mathrm{MPa})$ \\
\hline HPB300 & 6.5 & 315 & 465 & $2.14 \times 10^{5}$ \\
HRB400 & 12 & 448 & 615 & $1.98 \times 10^{5}$ \\
Galvanized wire & 2.2 & 416 & 489 & $1.49 \times 10^{5}$ \\
Galvanized wire & 4 & 410 & 480 & $1.57 \times 10^{5}$ \\
\hline
\end{tabular}

$2.55 \times 10^{4} \mathrm{MPa}$. On the basis of similarity analysis, $8 \#$ galvanized wire with equal strength was used to substitute steel bars with diameter of less than $6.5 \mathrm{~mm}$. The measured mechanical properties of steel bars are shown in Table 3, where $d$ refers to diameter, $f_{y}$ refers to yield strength, $f_{u}$ refers to tensile strength, and $E_{s}$ refers to the modulus of elasticity.

2.2. Specimen Design. Four trussets three-storey cast-in-situ phosphogypsum-reinforced concrete grid frame composite walls were made in a $1 / 5$ reduced scale. The serial numbers were ZHQ1-ZHQ4. Cast-in-situ phosphogypsum was filled in the reinforced concrete grid frame (Figure 8(a)). At the same time, three trussets three-storey pure reinforced concrete grid frames, numbered KJ1-KJ3 (Figure 8(b)), were made for comparative experiment. The same reinforcement was adopted by all the concrete members of the specimens (Figure 8(c)). The size and reinforcement of specimens are shown in Figure 8.

2.3. Loading Device. After the specimens were installed on the foundation through anchor bolts, the horizontal loading was applied to the end on the top floor beam through a $25 \mathrm{~T}$ MTS actuator, and the loading end of the actuator was connected to the specimens through a 25 -millimeter-diameter round steel clamp. To avoid the eccentric effect outside the plane during loading, a lateral support with rollers was arranged around the loading end of the actuator and on both sides of the specimen. The vertical load on the top of the specimen was applied and maintained constant by using a 50 T hydraulic jack. A roller was arranged between the jack and the specimen to eliminate the constraint effect on top of the specimen. The test loading device is shown in Figure 9.

2.4. Loading System. Different vertical loads are applied to each specimen, and the axial compression ratio calculated according to formula (1) is shown in Table 4 . After vertical load 


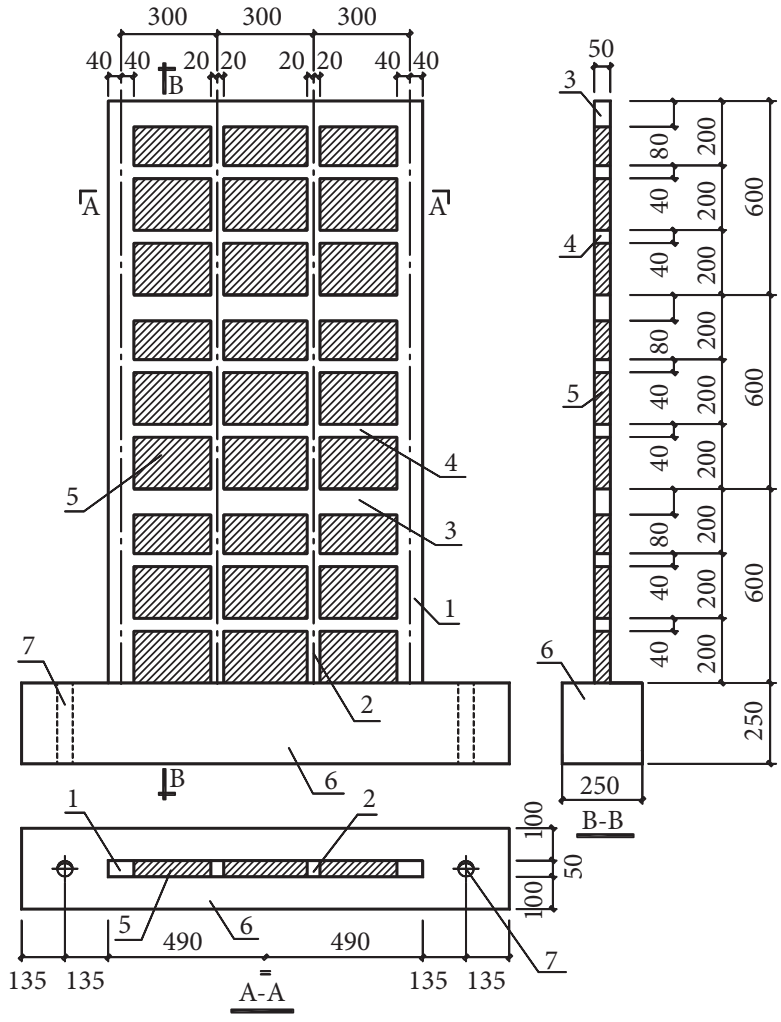

(a)
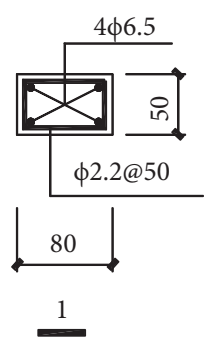

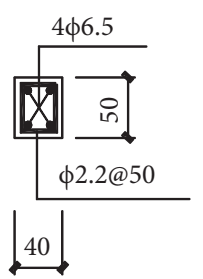

2

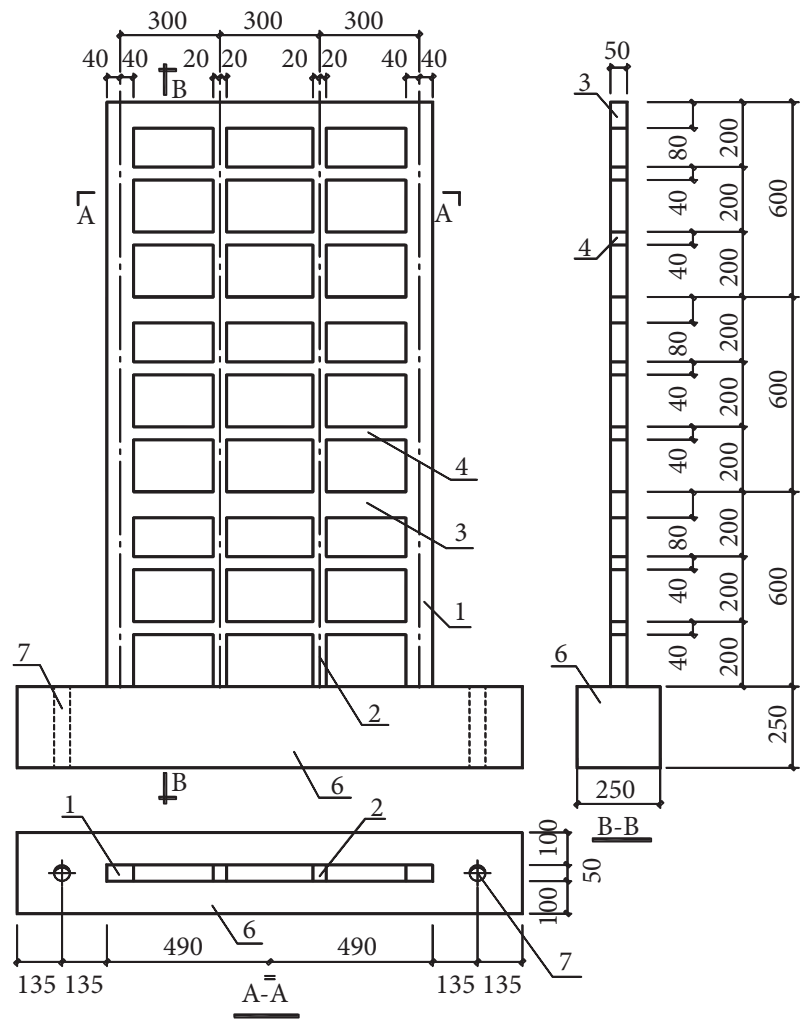

(b)
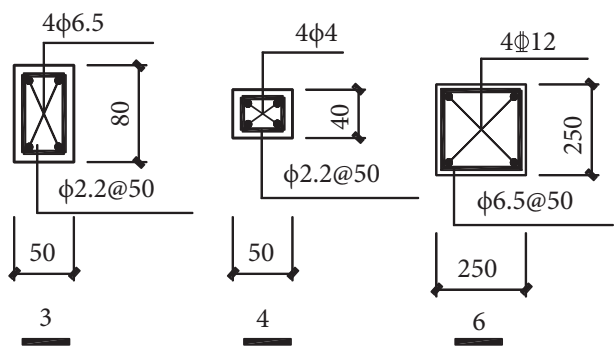

(c)

Figure 8: Geometry size and reinforcement of the specimen. (a) Specimen KJ. (b) Specimen ZHQ. (c) Reinforcement of concrete members. (1) Side pillar; (2) center pillar; (3) floor beam; (4) interstorey beams; (5) cast-in-situ phosphogypsum; (6) foundation beam; (7) anchor bolt hole.

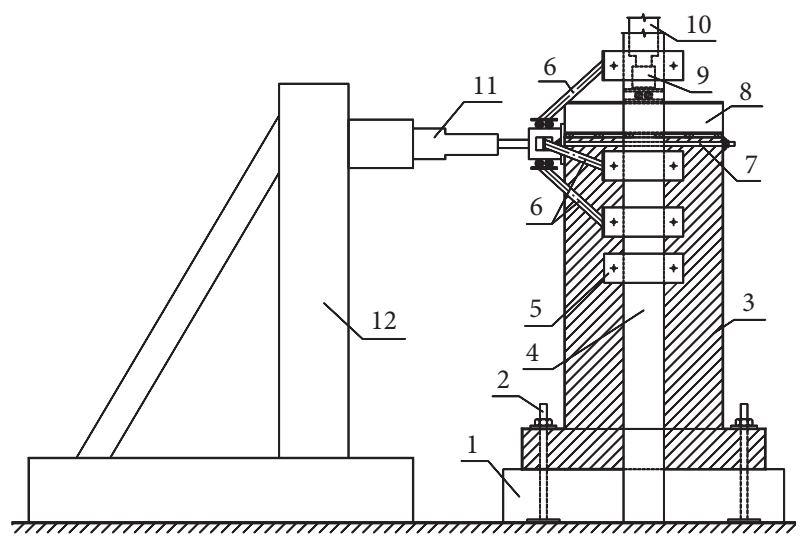

(a)

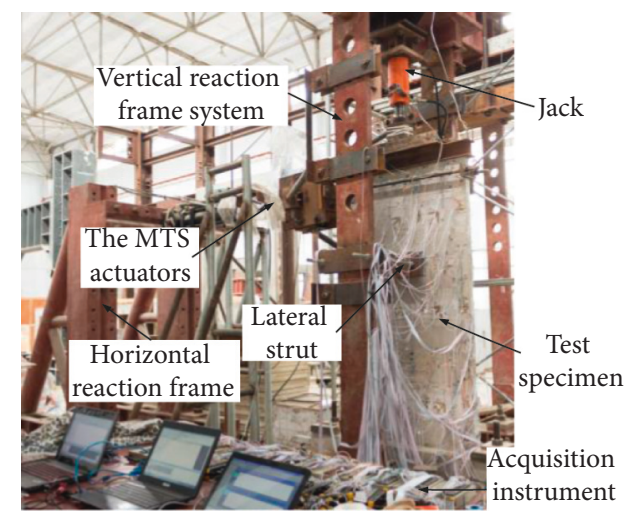

(b)

Figure 9: Test loading equipment. (a) Installation diagram. (1) Foundation; (2) sill anchor; (3) test specimen; (4) door type reaction frame; (5) lateral bracing; (6) lateral support at loading end; (7) round steel clamp; (8) vertical force distribution beam; (9) load transducer; (10) jack; (11) the MTS actuators; (12) triangular counter frame. (b) Picture of real products. 
TABLe 4: Axial compression ratio of specimen.

\begin{tabular}{lccccccc}
\hline Specimen number & KJ1 & KJ2 & KJ3 & ZHQ1 & ZHQ2 & ZHQ3 & ZHQ4 \\
\hline Axial compression ratio & 0.072 & 0.103 & 0.127 & 0.107 & 0.108 & 0.167 & 0.154 \\
\hline
\end{tabular}

is constant, horizontal loads were applied through displacement loading, as shown in Figure 10. Under the yield condition of the specimens, the strain of the longitudinal bar at the bottom of the side column reached the yield strain of the steel bar [22]. The specimen was loaded once per stage before cracking. After cracking, three cycles were loaded per stage of displacement. The loading was not stopped until the longitudinal reinforcement yielded and concrete was crushed.where $n$ is the axial compression ratio, $N$ is the vertical load, $f_{c}$ is the measured compressive strength of concrete, $f_{p}$ is the measured compressive strength of the cast-in-situ phosphogypsum, $A_{c}$ is the cross-sectional area of the column, and $A_{p}$ is the crosssectional area of the cast-in-situ phosphogypsum.

$$
n=\frac{N}{\sum f_{c} A_{c}+\sum f_{p} A_{p}} .
$$

2.5. Layout of Measuring Points. The physical quantities collected in the test were mainly the horizontal displacement of floor beams and foundations and the longitudinal strain of each member. The main measuring points of each specimen were arranged, as shown in Figure 11. The layout of the measuring points of reinforced concrete grid frame was the same as that of the reinforced concrete grid frame in the composite walls. In the numbers of measuring points, $H$ refers to the measuring point for displacement, and $L$ and $Z$ refer to the measuring points for the strain of longitudinal bars in the beams and columns, respectively. The computer data acquisition system was used to automatically collect and record the test data and observe and record the crack development and failure process of the specimens manually.

\section{Test Result and Discussion}

\subsection{Test Phenomena and Failure Characteristics}

3.1.1. Reinforced Concrete Grid Frame. When the vertical load of reinforced concrete grid frame is completed, there is no cracking on the surface of specimens. When the horizontal loading displacement is $12 \mathrm{~mm}$, vertical cracks appear in the joint area between the storey beam and side column and between the interstorey beam and middle column; cracks develop in the joint area between the storey beam and side column; and oblique cracks appear. When the horizontal loading displacement is $25 \mathrm{~mm}$, cross cracks appear in the joint area between the storey beam and side column and between the interstorey beam and middle column, and lateral cracks appear on the side of the side column. When the horizontal displacement is loaded to $75 \%$ of the failure displacement, oblique cracks appear in the foot area of side columns, and local failure of concrete occurs in the cross cracks of beam-column joints, with increasing transverse cracks of side columns. When the horizontal displacement is

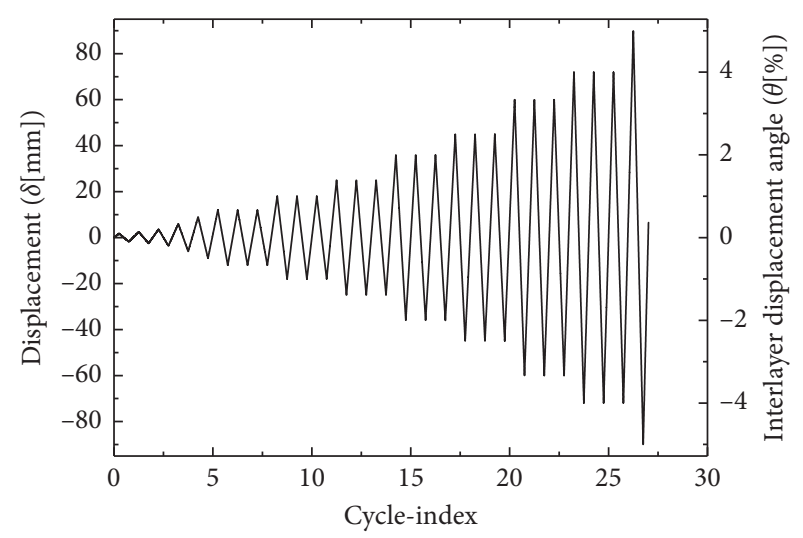

Figure 10: Loading cycles.

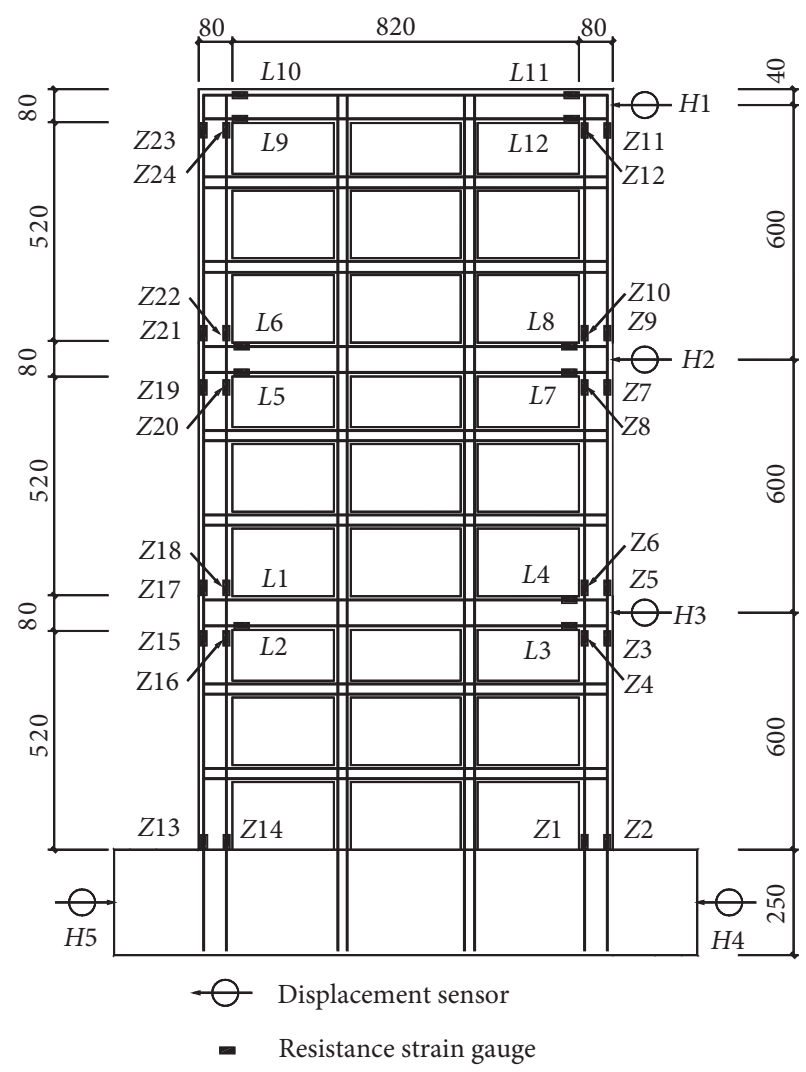

Figure 11: Layout of measuring point.

loaded to the failure displacement, original cracks increase gradually, the concrete is crushed, the steel bar buckles and the specimens are damaged. The failure of specimens is shown in Figure 12.

3.1.2. Cast-In-Situ Phosphogypsum-Reinforced Concrete Grid Frame Composite Wall. When the vertical load of cast-in- 


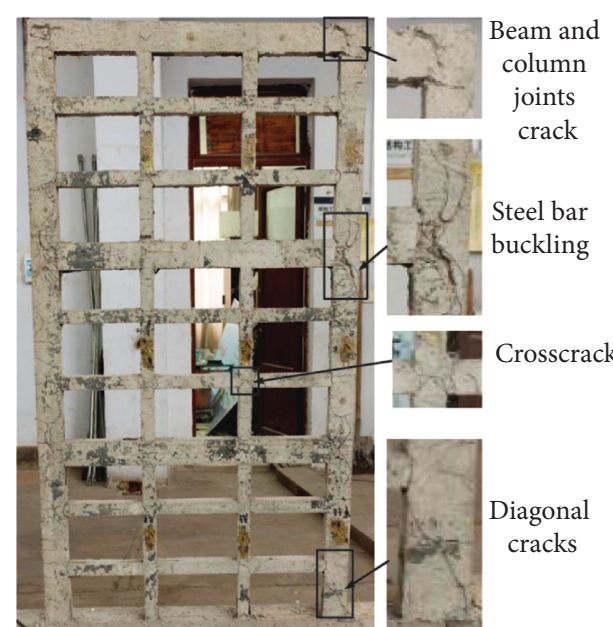

(a)

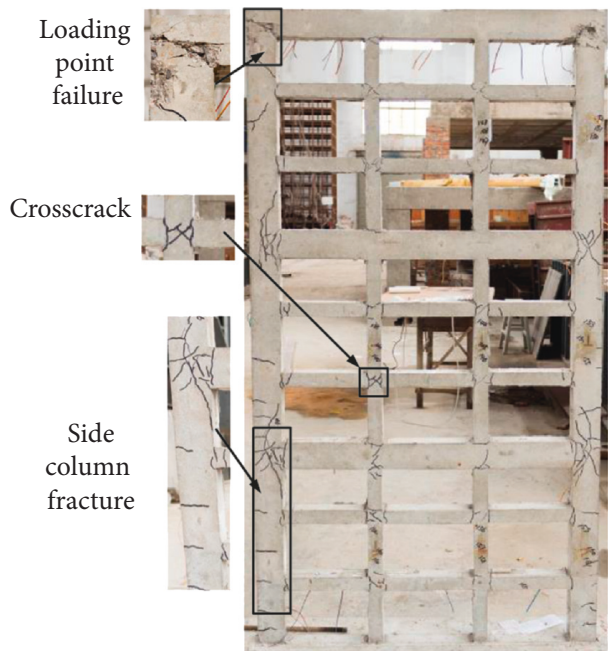

(c)

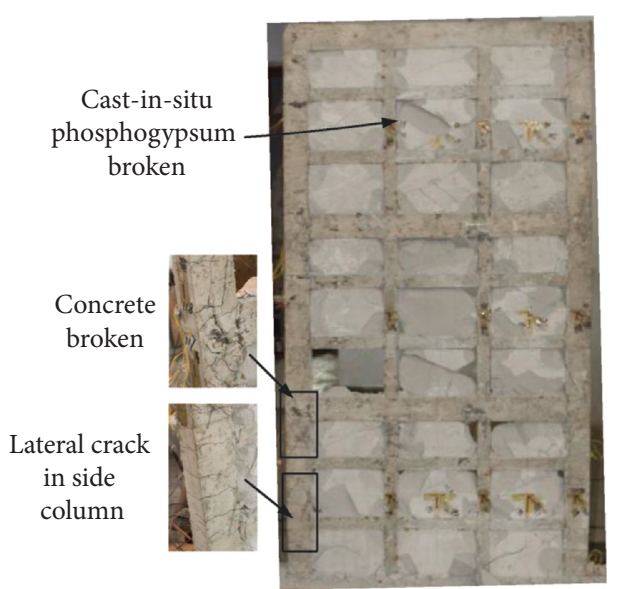

(e)

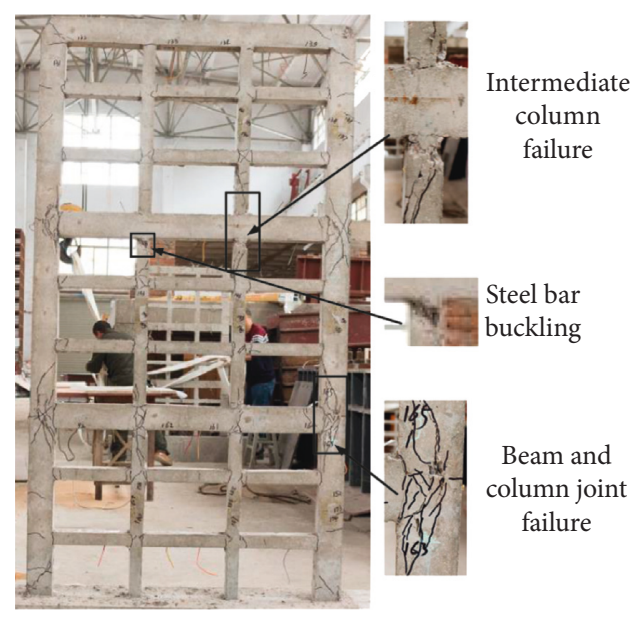

(b)

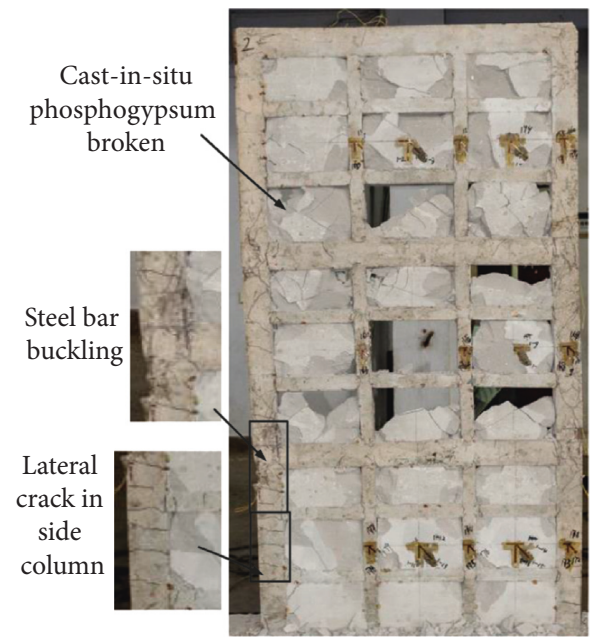

(d)

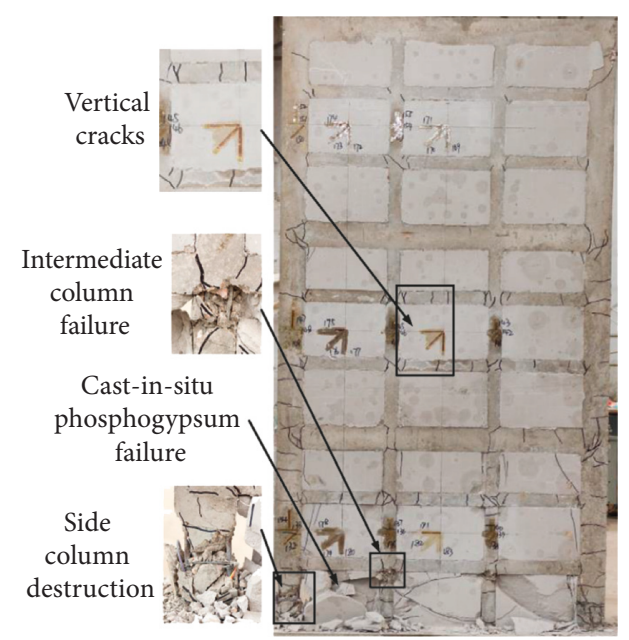

(f)

FIgURe 12: Continued. 


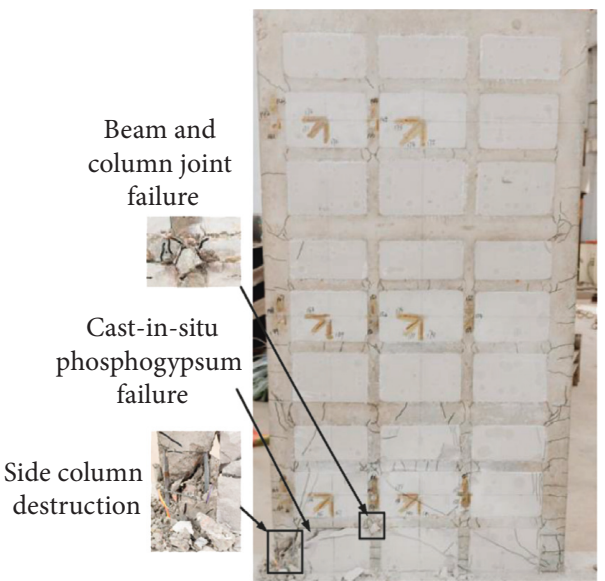

(g)

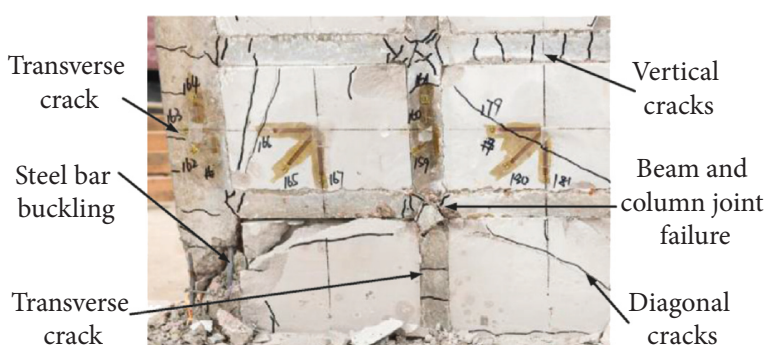

(h)

FIgURE 12: Failure modes of each specimen. (a) Specimen KJ1. (b) Specimen KJ2. (c) Specimen KJ3. (d) Specimen ZHQ1. (e) Specimen ZHQ2. (f) Specimen ZHQ3. (g) Specimen ZHQ4. (h) Details of the damage.

situ phosphogypsum-reinforced concrete grid frame composite wall is completed, there is no cracking on the surface of specimens. At the early stage of horizontal displacement loading, slip cracks appear at the joint of cast-in-situ phosphogypsum and concrete. When the horizontal loading displacement is loaded to about $30 \%$ of the failure displacement, vertical cracks appear in the joint area between the storey beam and side column, oblique cracks appear in the joint area between the interstorey beam and middle column, and lateral cracks appear in the side of the side column. When the horizontal displacement is loaded to $75 \%$ of the failure displacement, the corner of cast-in-situ phosphogypsum of ZHQ1 and ZHQ2 is broken, oblique cracks appear in the joint area between the storey beam and side column, and many oblique cracks appear in cast-in-situ phosphogypsum, with increasing transverse cracks of side columns. The corner of the cast-in-situ phosphogypsum of ZHQ3 and ZHQ4 is broken, vertical cracks appear in the middle of the lower part of the interstorey beam, and transverse cracks appear at the bottom of the middle column. Many oblique cross cracks appear in the beam-column joint area, and vertical fracture cracks appear at the bottom of the interstorey beam. When the horizontal displacement is loaded to the failure displacement, original cracks on ZHQ1 and ZHQ2 continue to develop, cast-in-situ phosphogypsum crushes and falls off, the concrete in the beam-column joint area is broken, steel bars are exposed and buckled, and the specimen is damaged. On the lower part of ZHQ3 and ZHQ4, splitting failure occurs on phosphogypsum, the transverse crack width of the side columns increases gradually, the concrete at the root of the side columns is broken, the steel bars are exposed and buckled, and the specimens are damaged. The failure of specimens is shown in Figure 12.

3.2. Hysteretic Curve. Figure 13 shows the load-displacement hysteretic curve of each specimen at the horizontal loading point, where $F$ refers to the horizontal load of the specimens, and $\delta$ refers to the horizontal displacement of the specimens. The following information can be derived from Figure 13:

(1) At the early stage of loading, the hysteretic curves of all specimens are basically fusiform, and residual deformation is small. Under the horizontal displacement loading, the hysteretic curve inclines to the displacement axis. The area around the curve and the energy dissipation capacity increase. However, under the same loading level, the hysteretic loop area of the second loading is smaller than that of the first loading.

(2) For reinforced concrete grid frame, the hysteretic curve of KJ2 is fuller than that of the two other specimens. Before reaching the peak load, the hysteretic curves of the specimens become similar in shape with kneading phenomenon. After reaching the peak load, the kneading phenomena of KJ1 and $\mathrm{KJ} 3$ hysteretic curves are more serious than that of $\mathrm{KJ} 2$, and their enclosed areas are smaller. When the loading displacement was $12 \mathrm{~mm}$, local damage occurred to specimen $\mathrm{KJ} 3$, resulting in a gap in the hysteretic curve, and the area enclosed by the hysteretic loop became smaller.

(3) For cast-in-situ phosphogypsum-reinforced concrete grid frame composite wall, the curves of ZHQ1 and ZHQ2 are roughly the same with obvious kneading phenomenon, and the hysteretic curves of ZHQ3 and ZHQ4 are slightly full. Compared with ZHQ1 and ZHQ3, when the axial compression ratio is relatively large, the hysteresis curve is fuller and the bearing capacity is increased.

(4) It can be seen that the hysteresis curve of the cast-insitu phosphogypsum-reinforced concrete grid frame composite wall is fuller than the reinforced concrete grid frame, and the enclosed area is larger and the energy consumption is higher. 


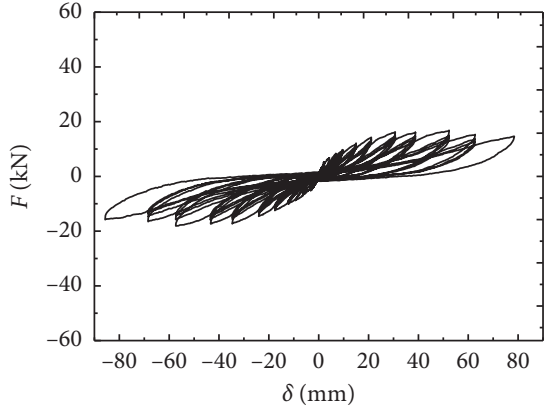

(a)

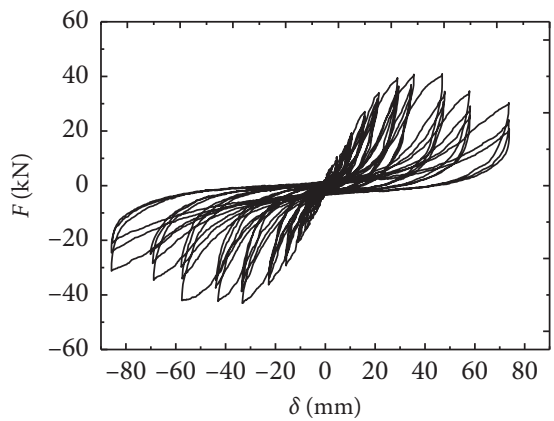

(d)

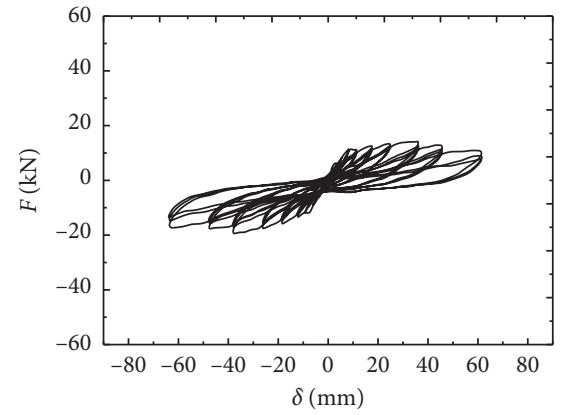

(b)

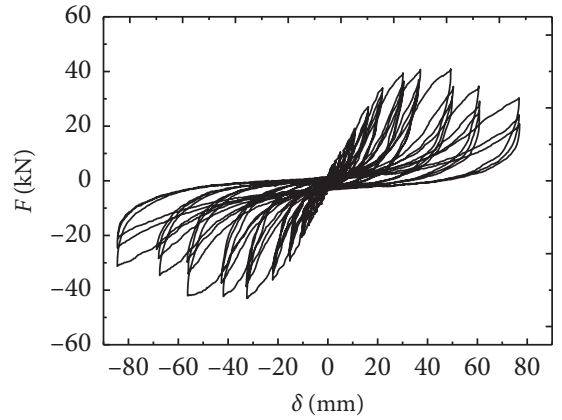

(e)

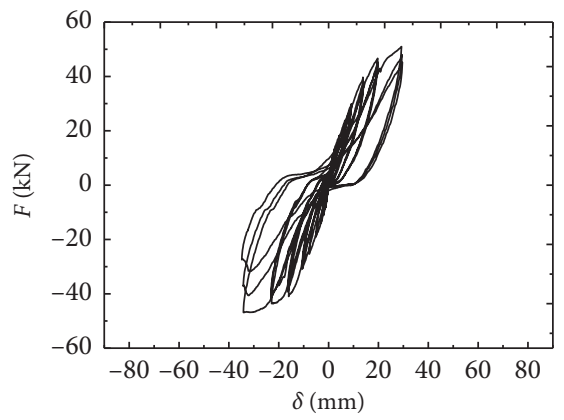

(g)

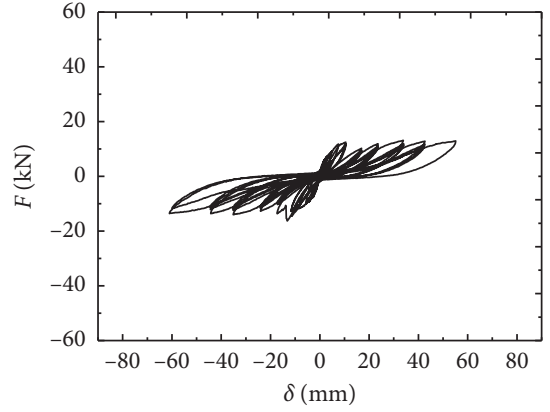

(c)

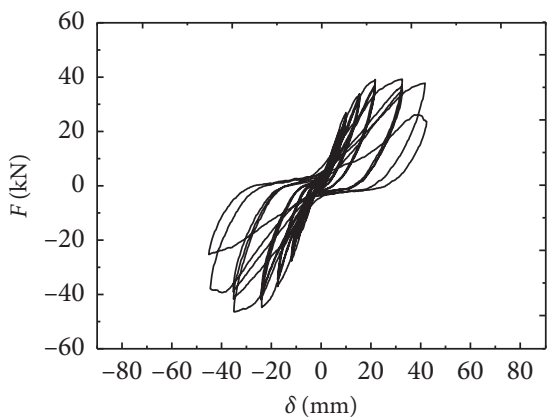

(f)

FIgURE 13: Hysteretic curves. (a) Specimen KJ1. (b) Specimen KJ2. (c) Specimen KJ3. (d) Specimen ZHQ1. (e) Specimen ZHQ2. (f) Specimen ZHQ3. (g) Specimen ZHQ4.

3.3. Skeleton Curve. The skeleton curve is the envelope curve formed by connecting the peak points of the first cycle of each loading stage of the hysteretic curve. The skeleton curves of the specimens are shown in Figure 14.

The following information can be derived from Figure 14:

(1) At the early stage of loading, the skeleton curve is basically linear. As the horizontal displacement increases gradually, the skeleton curve begins to bend and rise. After reaching the peak, the skeleton curve gradually decreases until the specimen is destroyed.

(2) For reinforced concrete grid frame, the skeleton curves are similar before yielding under different axial compression ratios. After the specimen yields, a certain difference is observed in the skeleton curve. The skeleton curves tend to be gentle. This finding indicates that the concrete grid frame has strong deformation capacity.
(3) For cast-in-situ phosphogypsum-reinforced concrete grid frame composite wall, the skeleton curves of ZHQ1 and ZHQ2 have obvious ascending and descending sections, respectively. The skeleton curves of ZHQ3 and ZHQ4 have obvious ascending sections but no obvious descending sections. In the case of the same displacement, the load of ZHQ4 is the largest, the load of $\mathrm{ZHQ} 3$ is the second, and the load of the other two specimens is the smallest. This finding indicates that the peak load increases with the axial compression ratio. The descending section of the skeleton curve is relatively abrupt. The stiffness of the specimen degenerates rapidly, and the deformation ability is low.

(4) The skeleton curves of KJ2 and ZHQ1 have obvious ascending and descending sections, respectively, with strong deformation capacity. The bearing capacity of the cast-in-situ phosphogypsum-reinforced concrete 


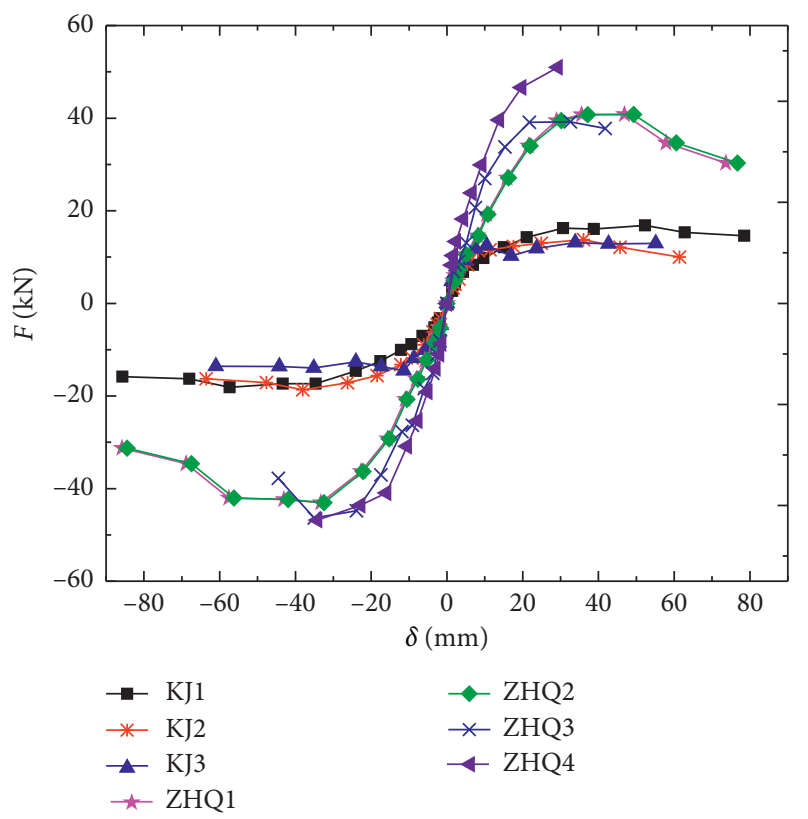

FIGURE 14: Skeleton curve.

grid frame composite wall is higher than the reinforced concrete grid frame. This finding shows that the addition of cast-in-situ phosphogypsum can evidently improve the bearing capacity of composite walls.

3.4. Bearing Capacity. The load and displacement at the measured characteristic points of the specimens are listed in Table 5. The following information can be derived from Table 5:

(1) For reinforced concrete grid frame, the comparison of $\mathrm{KJ} 1$ and $\mathrm{KJ} 2$ indicates that the load of the specimens increases with the axial compression ratio. Among them, the cracking loading increases more obviously. Given the increase of horizontal displacement, the specimens enter the yielding stage too early due to the high axial compression ratio of KJ3. Then, the bearing capacity of specimens obviously decreases. Finally, the bearing capacity of the specimens becomes smooth.

(2) For cast-in-situ phosphogypsum-reinforced concrete grid frame composite wall, the comparison of ZHQ1 and ZHQ2 shows that the axial compression ratios are approximately the same; thus, the load and displacement of specimens are also roughly the same. Meanwhile, the comparison of ZHQ1 and ZHQ3 shows that when the axial compression ratios are different, the load and displacement of specimens also vary considerably. When the axial compression ratio is large, the corresponding cracking displacement occurs earlier and the cracking load is also large. In addition, the characteristic displacements of ZHQ3 appear earlier than those of ZHQ1. However, the peak and limit loads of ZHQ3 are larger than those of ZHQ1.
(3) In comparison with $\mathrm{KJ} 2, F_{\mathrm{cr}}, F_{y}, F_{m}$, and $F_{u}$ of ZHQ1 increase by $33.6 \%, 151.81 \%, 158.21 \%$, and $134.39 \%$, respectively, under the same axial compression ratio. This finding shows that the addition of cast-in-situ phosphogypsum can effectively improve the bearing capacity of composite wall.

3.5. Ductility Coefficient and Limit Displacement Angle. The ductility coefficient of the structure refers to the capability of the structure to continue increasing its deformation after yielding. It is measured by the displacement ductility coefficient $\mu=\delta_{u} / \delta_{y}$. The limit displacement angle at specimen failure is $\theta_{u}=\delta_{u} / H$, where $H$ refers to the total wall height. The displacement ductility coefficient $\mu$ and limit displacement angle $\theta_{u}$ of specimens are shown in Table 5 .

The following information can be derived from Table 5:

(1) For reinforced concrete grid frame, the positive displacement ductility coefficients of specimens are in the range of 3.4-3.6, with a mean value of 3.510. The reverse displacement ductility coefficients of specimens are in the range of 3.2-3.5, with a mean value of 3.414. The limit displacement angle $\theta_{u}$ decreases with the increase of the axial compression ratio, between $1 / 21$ and $1 / 33$, and the average value of $1 / 27$.

(2) For cast-in-situ phosphogypsum-reinforced concrete grid frame composite wall, the positive displacement ductility coefficients of specimens are in the range of 3.2-3.9, with a mean value of 3.648. The reverse displacement ductility coefficients of specimens are in the range of 3.1-4.2, with a mean value of 3.572. The limit displacement angle decreases with the increase of axial compression ratio, and the limit displacement angle of ZHQ4 is the smallest, while 
TABLE 5: Test results of characteristic points.

\begin{tabular}{|c|c|c|c|c|c|c|c|c|c|c|c|}
\hline \multirow{2}{*}{$\begin{array}{l}\text { Specimen number } \\
\text { (axial compression ratio) }\end{array}$} & \multirow{2}{*}{ Loading direction } & \multicolumn{2}{|c|}{ Cracking point } & \multicolumn{2}{|c|}{ Yield point } & \multicolumn{2}{|c|}{ Peak point } & \multicolumn{2}{|c|}{ Ultimate point } & \multirow{2}{*}{$u$} & \multirow{2}{*}{$\theta_{u}$} \\
\hline & & $F_{\mathrm{cr}}(\mathrm{kN})$ & $\delta_{\mathrm{cr}}(\mathrm{mm})$ & $F_{y}(\mathrm{kN})$ & $\delta_{y}(\mathrm{~mm})$ & $F_{m}(\mathrm{kN})$ & $\delta_{m}(\mathrm{~mm})$ & $F_{u}(\mathrm{kN})$ & $\delta_{u}(\mathrm{~mm})$ & & \\
\hline KJ1 & Reverse & 8.810 & 9.353 & 14.587 & 24.056 & 18.110 & 57.364 & 15.829 & 85.668 & 3.566 & $1 / 21$ \\
\hline$(0.072)$ & Forward & 8.334 & 6.874 & 14.274 & 21.104 & 16.817 & 52.303 & 14.611 & 78.478 & 3.488 & $1 / 23$ \\
\hline $\mathrm{KJ} 2$ & Reverse & 11.776 & 9.190 & 15.609 & 18.463 & 18.677 & 38.074 & 16.278 & 63.580 & 3.444 & $1 / 28$ \\
\hline$(0.103)$ & Forward & 11.402 & 8.311 & 12.319 & 17.567 & 13.774 & 36.075 & 9.996 & 61.419 & 3.496 & $1 / 29$ \\
\hline $\mathrm{KJ} 3$ & Reverse & 11.854 & 8.691 & 13.642 & 17.334 & 13.968 & 35.160 & 13.580 & 61.029 & 3.521 & $1 / 29$ \\
\hline$(0.127)$ & Forward & 11.810 & 7.532 & 10.249 & 16.921 & 13.106 & 33.869 & 12.937 & 55.147 & 3.259 & $1 / 33$ \\
\hline ZHQ1 & Reverse & 16.385 & 8.084 & 36.293 & 22.725 & 43.054 & 33.296 & 31.254 & 85.784 & 3.775 & $1 / 21$ \\
\hline$(0.107)$ & Forward & 14.581 & 8.058 & 34.032 & 21.537 & 40.738 & 35.534 & 30.330 & 73.619 & 3.418 & $1 / 24$ \\
\hline ZHQ2 & Reverse & 16.385 & 7.662 & 36.293 & 22.130 & 43.054 & 32.472 & 31.254 & 84.4522 & 3.816 & $1 / 21$ \\
\hline$(0.108)$ & Forward & 14.581 & 8.381 & 34.032 & 22.001 & 40.739 & 37.160 & 30.330 & 76.704 & 3.486 & $1 / 23$ \\
\hline ZHQ3 & Reverse & 20.626 & 6.022 & 27.701 & 11.869 & 46.333 & 35.064 & 37.755 & 44.522 & 3.751 & $1 / 40$ \\
\hline$(0.167)$ & Forward & 13.100 & 5.094 & 26.944 & 9.975 & 39.216 & 32.596 & 37.798 & 41.763 & 4.186 & $1 / 43$ \\
\hline ZHQ4 & Reverse & 19.112 & 5.129 & 30.837 & 10.518 & 46.828 & 34.178 & 46.828 & 34.178 & 3.249 & $1 / 53$ \\
\hline$(0.154)$ & Forward & 18.215 & 4.298 & 29.913 & 9.159 & 50.961 & 29.275 & 50.961 & 29.275 & 3.196 & $1 / 61$ \\
\hline
\end{tabular}

the limit displacement angle of ZHQ3 is the second. Among ZHQ1-ZHQ4, ZHQ3 has the largest ductility coefficient, followed by ZHQ1 and ZHQ2, and ZHQ4 has the smallest ductility coefficient. ZHQ1 and ZHQ2 have a large limit displacement angle.

(3) It can be seen that the ductility coefficient of the castin-situ phosphogypsum-reinforced concrete grid frame composite wall is slightly larger than the reinforced concrete grid frame, and the limit displacement angle of ZHQ1 and ZHQ2 in the composite wall is slightly larger than the reinforced concrete grid frame.

3.6. Attenuation of Bearing Capacity. The reduction factor of bearing capacity $\phi[23]$ is adopted to characterise the attenuation law of the bearing capacity of specimens. The reduction factor of the bearing capacity of specimens $\phi$ refers to the ratio of peak load of cycle 2 to that of cycle 1 under the same stage of loading. The relationship between $\phi$ and the horizontal displacement at the loading point is shown in Figure 15.

The following information can be derived from Figure 15:

(1) For reinforced concrete grid frame, the reduction factor of the bearing capacity $\phi$ of specimens remains in the range of $0.827-0.955$. This finding shows that all the specimens do not show serious bearing capacity attenuation.

(2) For cast-in-situ phosphogypsum-reinforced concrete grid frame composite wall, the reduction factor of the bearing capacity $\phi$ of specimens remains in the range of $0.626-1.0$. The attenuation of ZHQ1 and ZHQ2 is nearly the same, whereas that of ZHQ3 and ZHQ4 is relatively serious. When the displacement is less than the peak displacement, the bearing capacity reduction coefficient of $\mathrm{ZHQ} 3$ and $\mathrm{ZHQ} 4$ is greater than that of the other two specimens. When the displacement exceeds the peak displacement, the bearing capacity of ZHQ3 and ZHQ4 declines seriously.
Hence, the attenuation of specimens increases with the axial compression ratio. After loading to the peak, the reduction factor of bearing capacity evidently decreases. Moreover, the attenuation degree of the composite wall is slightly greater than the reinforced concrete grid frame.

3.7. Energy Dissipation. The energy dissipation of specimens is measured by the area surrounded by the hysteretic curve of the load-displacement curve. The equivalent viscous damping coefficients of all specimens under peak load and failure $h_{e}[24]$ are shown in Table 6 .

$$
h_{e}=\frac{S_{1}}{2 \pi\left(S_{2}+S_{3}\right)} \text {, }
$$

where $S_{1}$ refers to the energy dissipated by the components in a reverse and forward cycle, and $S_{2}$ and $S_{3}$ are the energy absorbed by an ideal elastic structure at the same displacement, as shown in Figure 16 [25].

The accumulated energy consumption $E$ refers to the sum of areas surrounded by hysteretic loops. The accumulated energy consumption by all specimens is normalised on the basis of the accumulated energy consumption by KJ1. The relative accumulated energy consumption $E_{r}$ is obtained, as shown in Figure 17.

From Table 6 and Figure 17, the following information can be derived:

(1) For reinforced concrete grid frame, the equivalent viscous damping coefficient $h_{e}$ of $\mathrm{KJ} 2$ is obviously higher than those of $\mathrm{KJ} 1$ and $\mathrm{KJ} 3$. The relative accumulated energy consumption of KJ2 and $\mathrm{KJ} 3$ is lower than that of KJ1. With the increase of axial compression ratio, the equivalent viscous damping coefficient $h_{e}$ of $\mathrm{KJ} 1$ and KJ2 increases gradually, and the relative accumulated energy consumed decreases accordingly.

(2) For cast-in-situ phosphogypsum-reinforced concrete grid frame composite wall, the equivalent viscous damping coefficient $h_{e}$ of ZHQ3 and ZHQ4 is obviously higher than those of two specimens. With the increase of axial compression ratio, the 


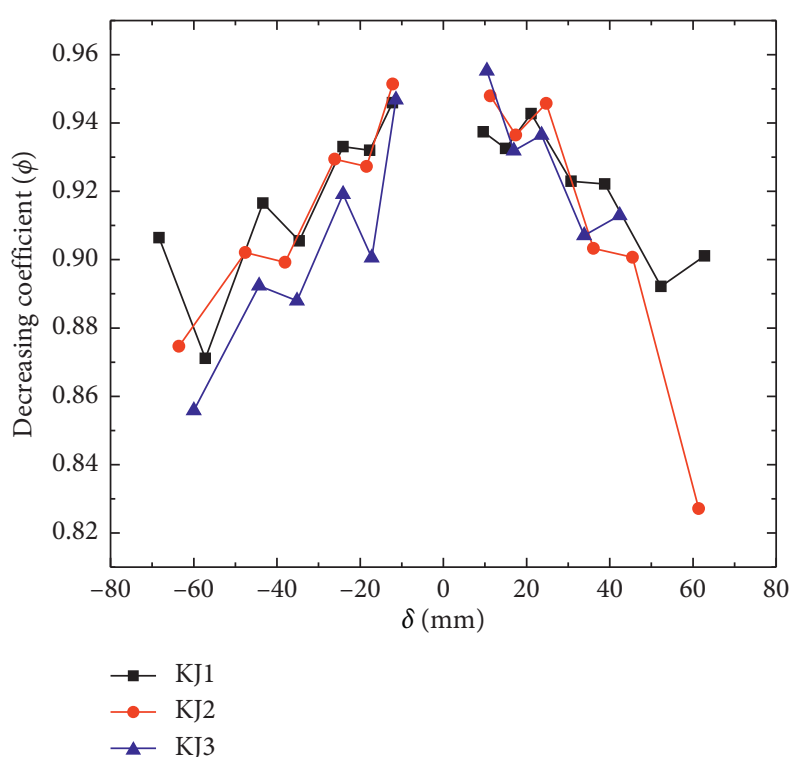

(a)

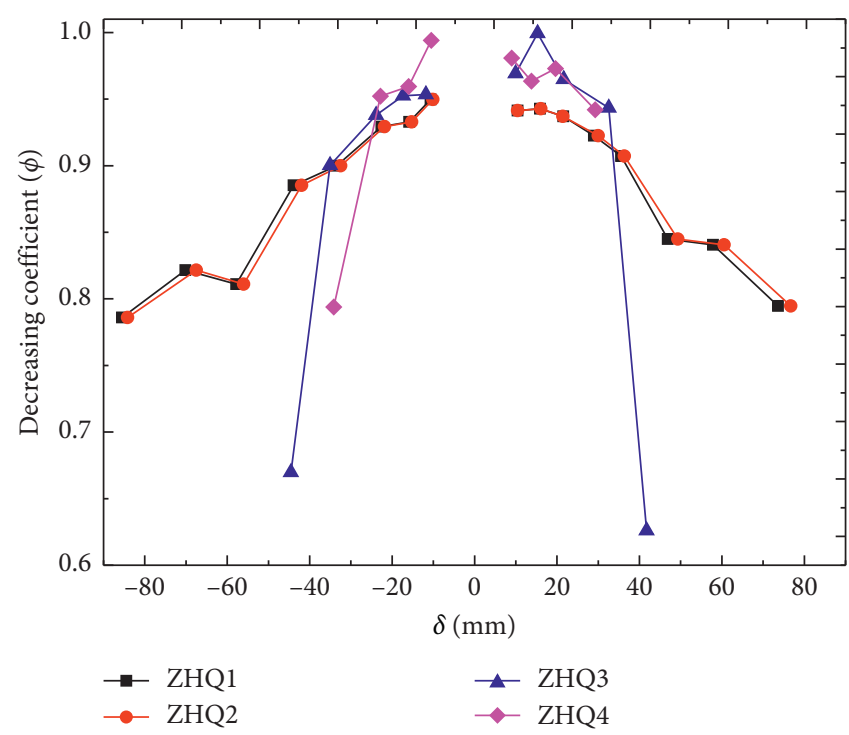

(b)

Figure 15: Bearing capacity degradation. (a) Concrete gird frame wall. (b) Cast-in-place phosphogypsum-reinforced concrete grid frame composite wall.

TABLE 6: Equivalent viscous damping coefficient $h_{e}$.

\begin{tabular}{lccccccc}
\hline $\begin{array}{l}\text { Specimen } \\
\text { number }\end{array}$ & KJ1 & KJ2 & KJ3 & ZHQ1 & ZHQ2 & ZHQ3 & ZHQ4 \\
\hline $\begin{array}{l}\text { Peak point } \\
\begin{array}{l}\text { Ultimate } \\
\text { point }\end{array}\end{array}$ & 0.092 & 0.129 & 0.088 & 0.083 & 0.084 & 0.132 & 0.129 \\
\hline
\end{tabular}

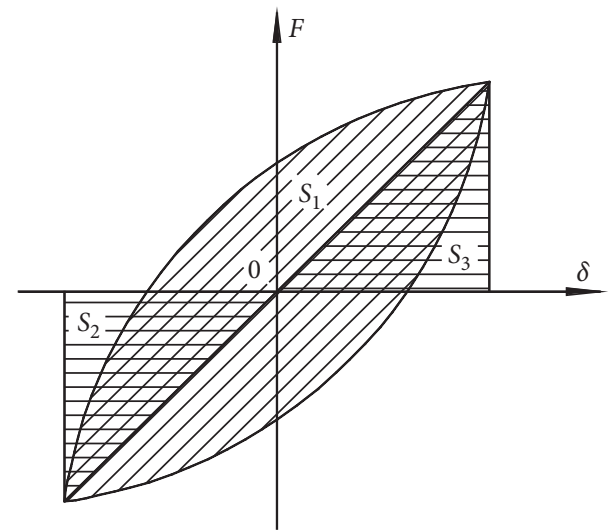

FIGURE 16: Calculation of equivalent viscous damping coefficient.

equivalent viscous damping of specimens increases gradually, and the relative accumulated energy consumption decreases accordingly.

(3) The relative accumulated energy consumption by $\mathrm{KJ} 2, \mathrm{KJ}$, and ZHQ1-ZHQ4 is approximately 0.84 , $0.55,2.13,2.16,1.31$, and 0.86 times of that of base contrast specimen KJ1, respectively.

This finding shows that the addition of cast-in-place phosphogypsum can effectively increase the energy consuming capacity of the reinforced concrete grid frame.

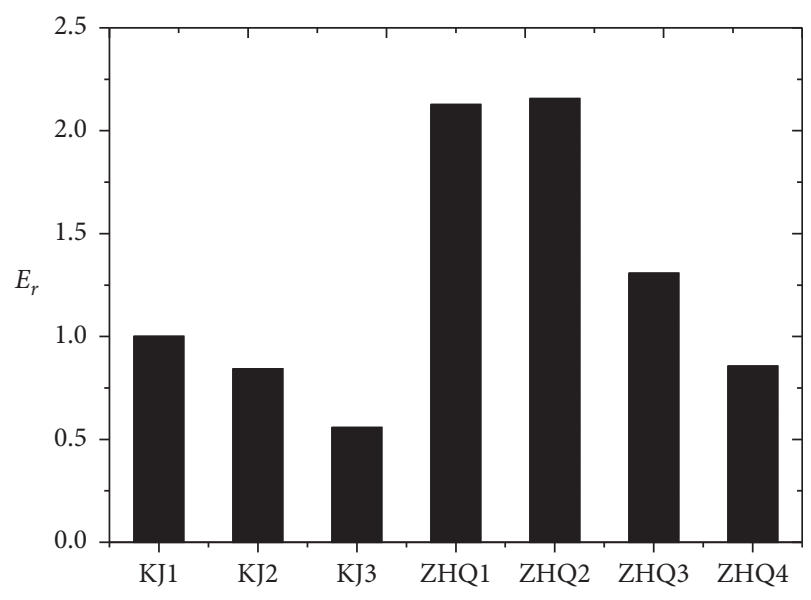

FIgURE 17: Relative accumulated energy consumption.

3.8. Stiffness Degradation. According to JGJ/T-2015 specification of testing methods for earthquake resistant buildings [22], the degree of stiffness degradation is measured by the slope of the connection between the peak points of positive load in the first hysteresis loop of each stage cycle. The calculation formula is as follows [26]:

$$
K_{i}=\frac{\left|+F_{i}\right|+\left|-F_{i}\right|}{\left|+\delta_{i}\right|+\left|-\delta_{i}\right|},
$$

where $+F_{i}$ and $-F_{i}$ refer to the positive and negative maximum loads of the first hysteresis loop under $i$ stage cycle loading, respectively, and $+\delta_{i}$ and $-\delta_{i}$ refer to the positive and negative maximum displacements of the first hysteresis loop under $i$ stage cycle loading, respectively. The stiffness degradation curves of all specimens are shown in Figure 18. 


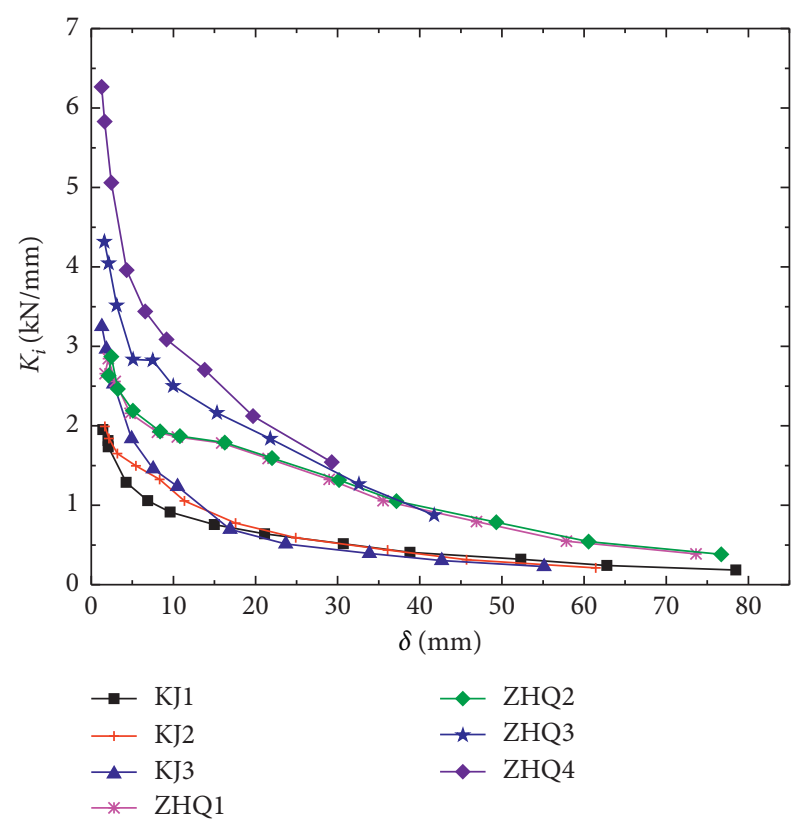

FIGURE 18: Stiffness degradation curve.

From the comparison of curves in Figure 18, the following information can be derived:

(1) The stiffness degradation laws in the loading process of specimens are consistent. The faster the stiffness attenuation is in the early stage of loading, the slower it is in the middle and late stages of loading, which gradually tends to be horizontal.

(2) For reinforced concrete grid frame, the initial stiffness of $\mathrm{KJ} 3$ is larger than those of $\mathrm{KJ} 1$ and $\mathrm{KJ} 2$. As the horizontal displacement increases, the stiffness of specimens decreases gradually. Among them, the stiffness degradation of $\mathrm{KJ} 3$ is rapid. When the horizontal displacement is approximately $18 \mathrm{~mm}$, the late stiffness of specimens is roughly the same and tends to be smooth.

(3) For cast-in-situ phosphogypsum-reinforced concrete grid frame composite wall, the initial stiffness of ZHQ4 is the highest, followed by that of ZHQ3. The stiffness of ZHQ1 and ZHQ2 is roughly the same. As the horizontal displacement increases, the stiffness degradation of ZHQ3 and ZHQ4 is fast. The stiffness of specimens decreases gradually. When the horizontal displacement is approximately $36 \mathrm{~mm}$, the late stiffness of specimens is roughly the same and tends to be smooth.

Hence, the stiffness of cast-in-situ phosphogypsumreinforced concrete grid frame composite wall is higher than that of reinforced concrete grid frame. This finding shows that the addition of cast-in-situ phosphogypsum can significantly improve the stiffness of composite wall.

3.9. Strain of Longitudinal Reinforcement. The measuring points of strain shown in Figure 11 are measured. Figure 18 shows the strain distribution of each specimen with the increase of loading displacement. The following information can be derived from Figures 11 and 19:

(1) For reinforced concrete grid frame, steel strain increases gradually with the displacement. In the strain of column longitudinal reinforcement, $Z 13$ has the largest strain at the base of column, and $L 1$ has the largest in the strain of beam longitudinal reinforcement. However, steel strain does not gradually reduce with the increase of the specimen height. Hence, the lower strain of the specimens is large, although the stress of the specimens is complex.

(2) For cast-in-situ phosphogypsum-reinforced concrete grid frame composite wall, steel strain increases gradually with the displacement. In the strain of column longitudinal reinforcement, $Z 13$ has the largest strain at the base of column, and $L 1$ has the largest in the strain of beam longitudinal reinforcement. Steel strain decreases with the increase of specimen height. Thus, the addition of cast-in-situ phosphogypsum can properly change the stress performance of specimens. The lower strain of the specimens is large, and the upper strain is small.

It can be seen that the addition of cast-in-situ phosphogypsum changes the stress of the reinforced concrete grid frame, which results in the difference between the steel strain of the composite wall and the steel strain of reinforced concrete grid frame.

3.10. Analysis of Failure Mechanism. The addition of cast-insitu phosphogypsum not only can improve the stress of reinforced concrete grid frame and its bearing capacity and stiffness but can also restrain the deformation of concrete and change the stress mechanism of specimens. Under horizontal load, cast-in-situ phosphogypsum and reinforced concrete grid frame works together. Cast-in-situ phosphogypsum is constrained by reinforced concrete grid frame. Meanwhile, the deformation of reinforced concrete grid frame is constrained by cast-in-situ phosphogypsum. Both conditions interact with each other, exert force together, and give full play to their respective performance. At the same time, cast-in-situ phosphogypsum has the property of microexpansion and can fully be in contact with the reinforced concrete grid frame. Hence, the deformation of both tends to coordinate and work together. When the horizontal load is small, the horizontal load is borne by the concrete grid frame. As the loading displacement increases, the deformation of reinforced concrete grid frame increases and cast-in-situ phosphogypsum is extruded to bear the horizontal load together. The horizontal load continues to increase with the displacement.

This finding shows that the collaborative work of cast-insitu phosphogypsum and reinforced concrete grid frame can effectively restrain each other and improve the bearing capacity and stiffness of the specimens. Then, cast-in-situ phosphogypsum is damaged with penetrated cracks, broken base of 

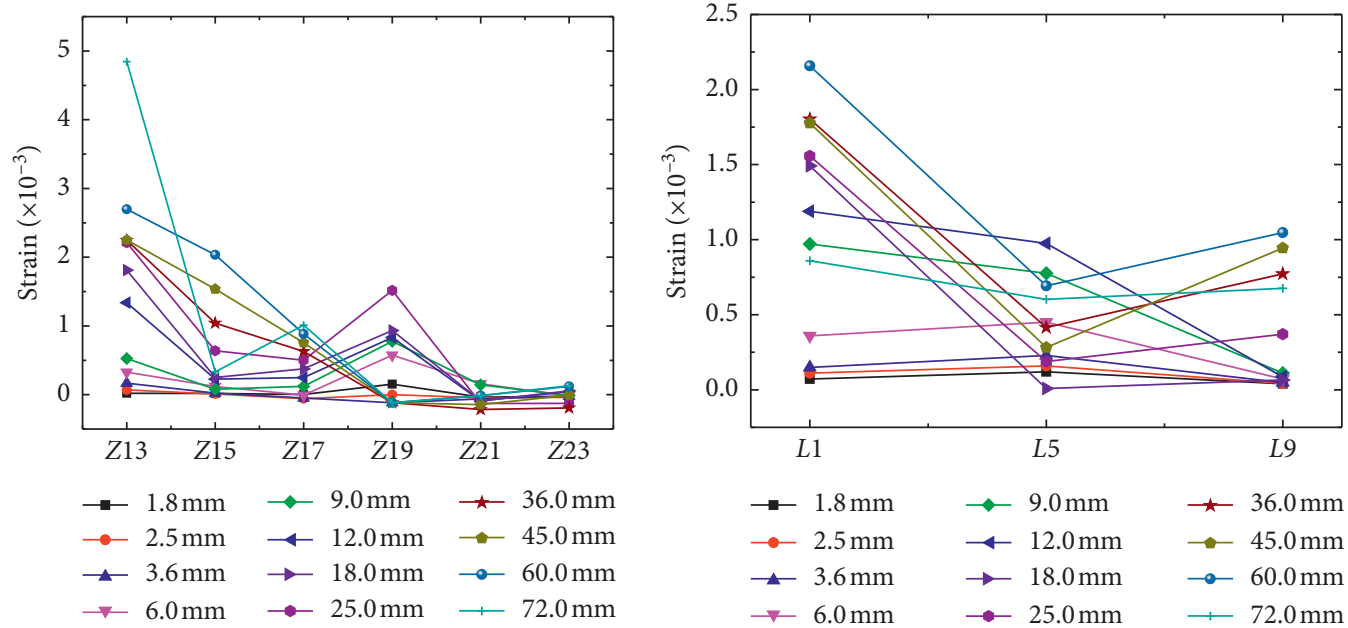

(a)
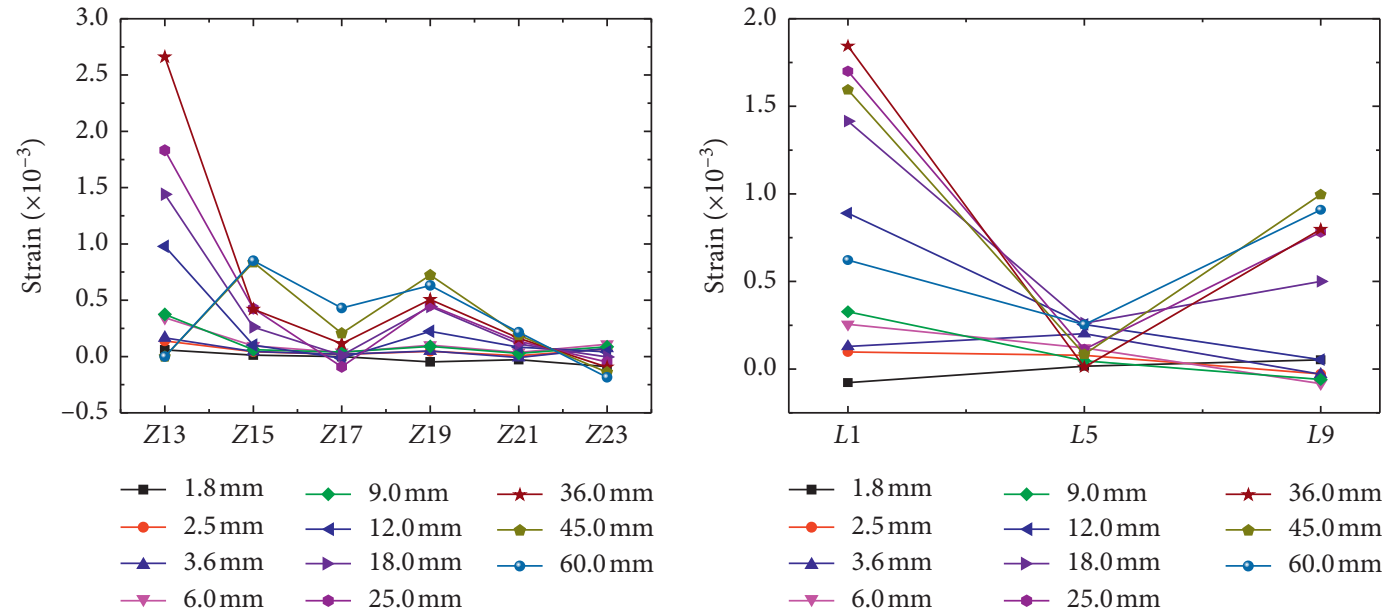

(b)
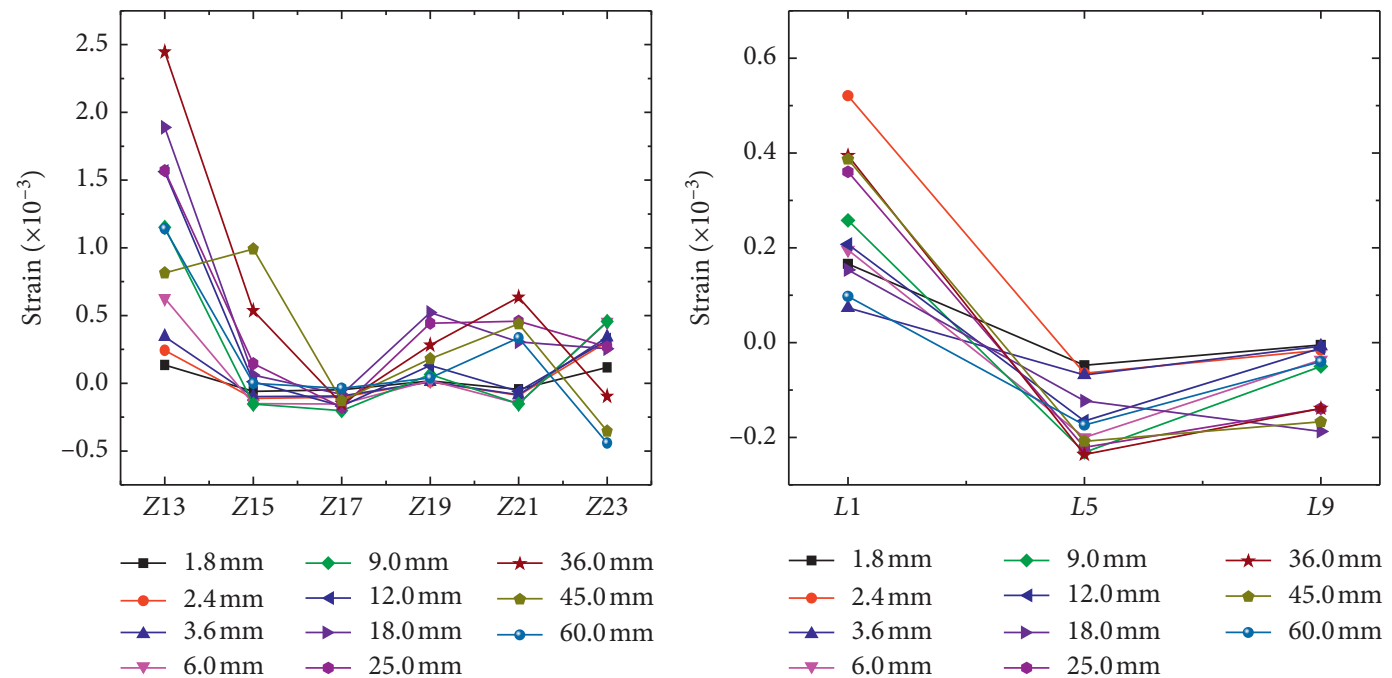

(c)

Figure 19: Continued. 

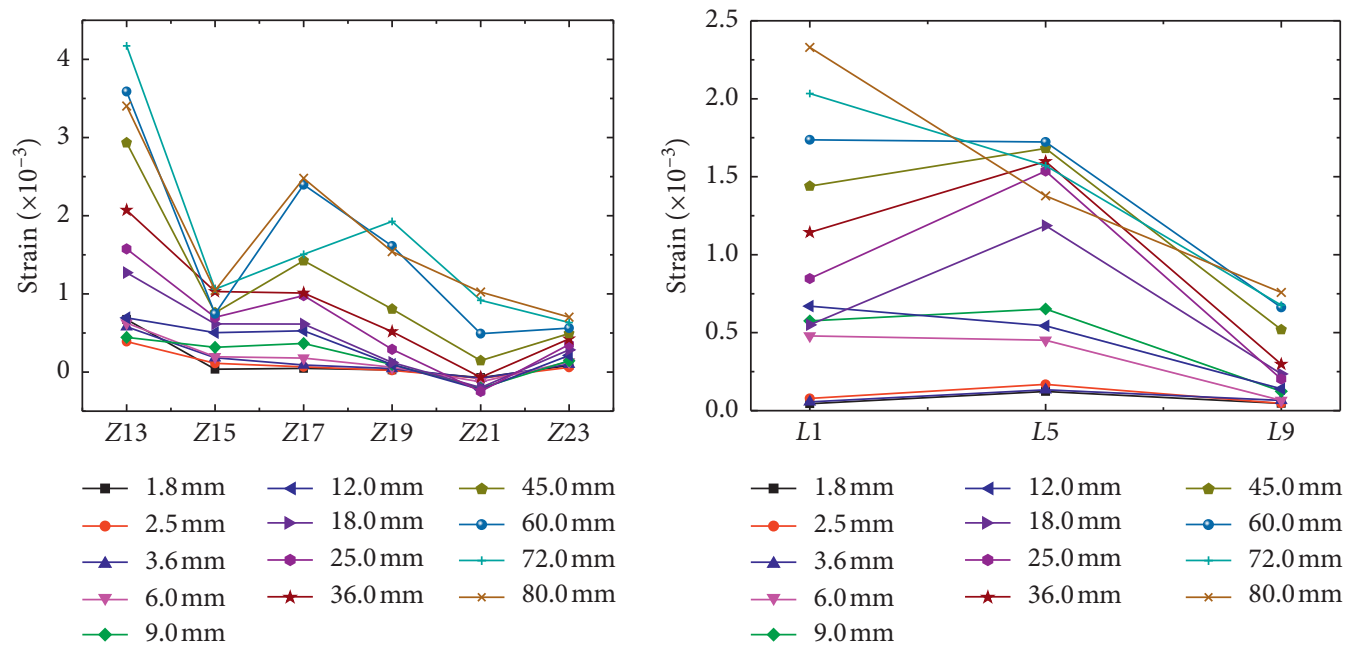

(d)
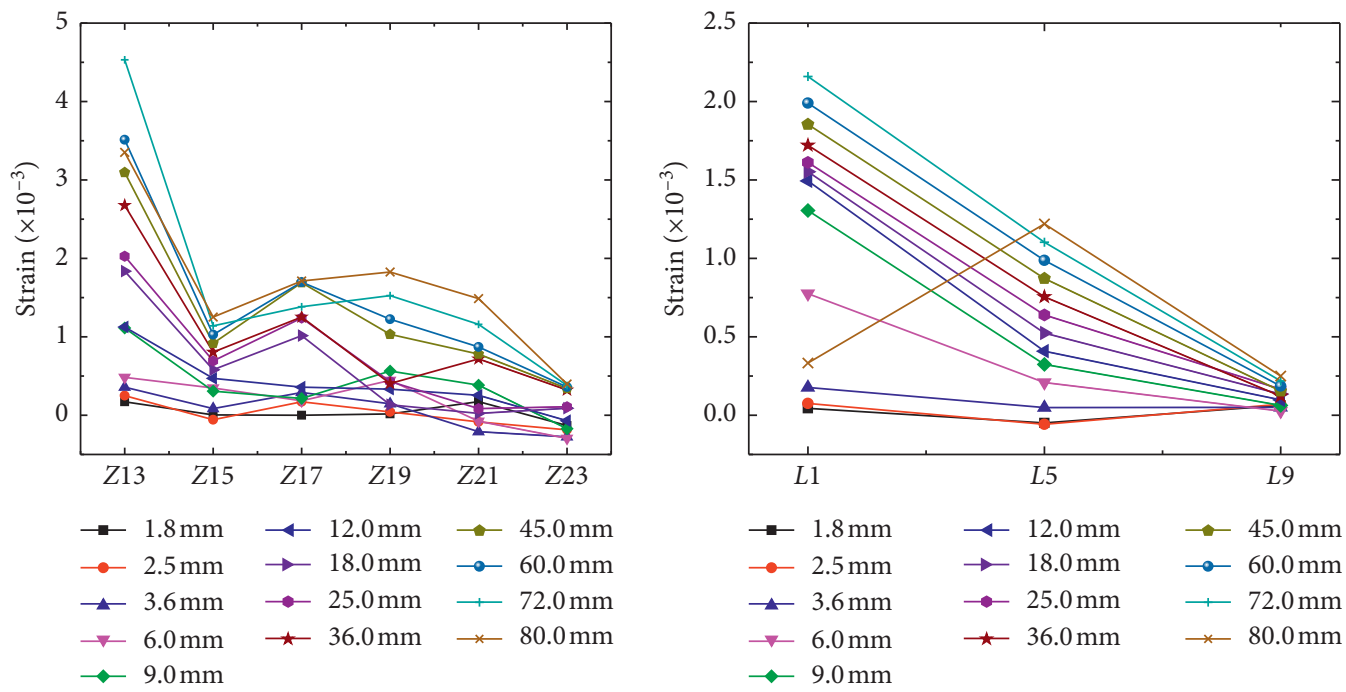

(e)
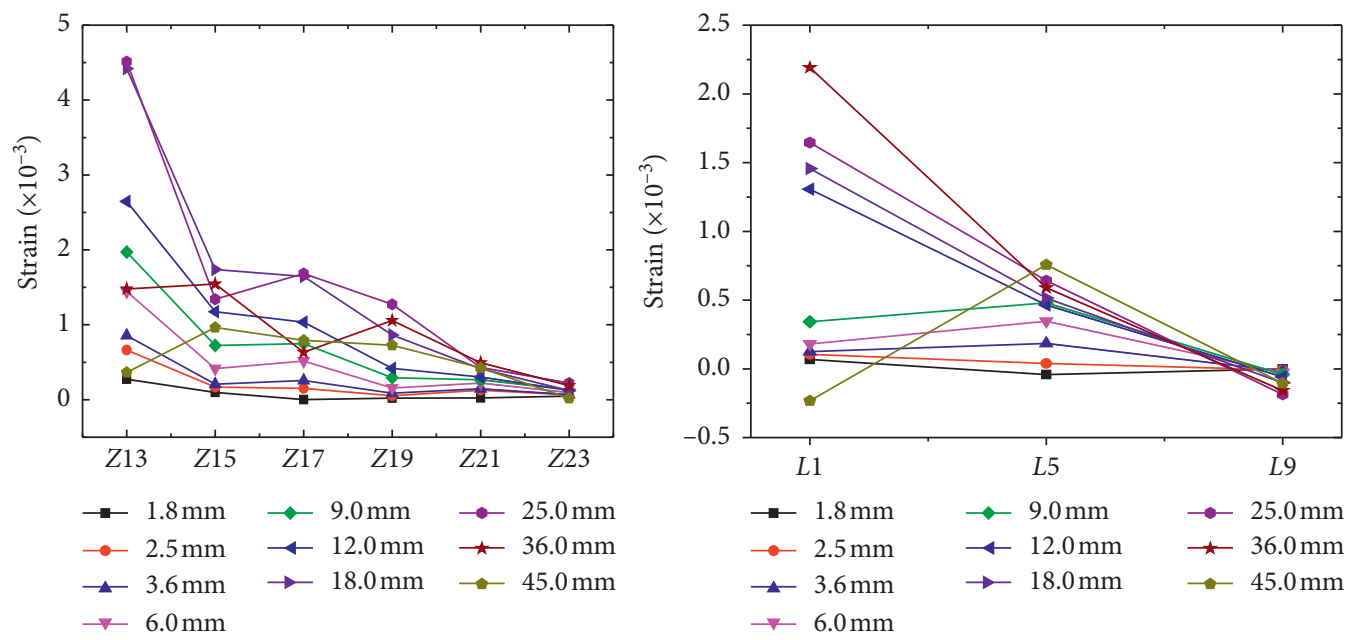

(f)

Figure 19: Continued. 

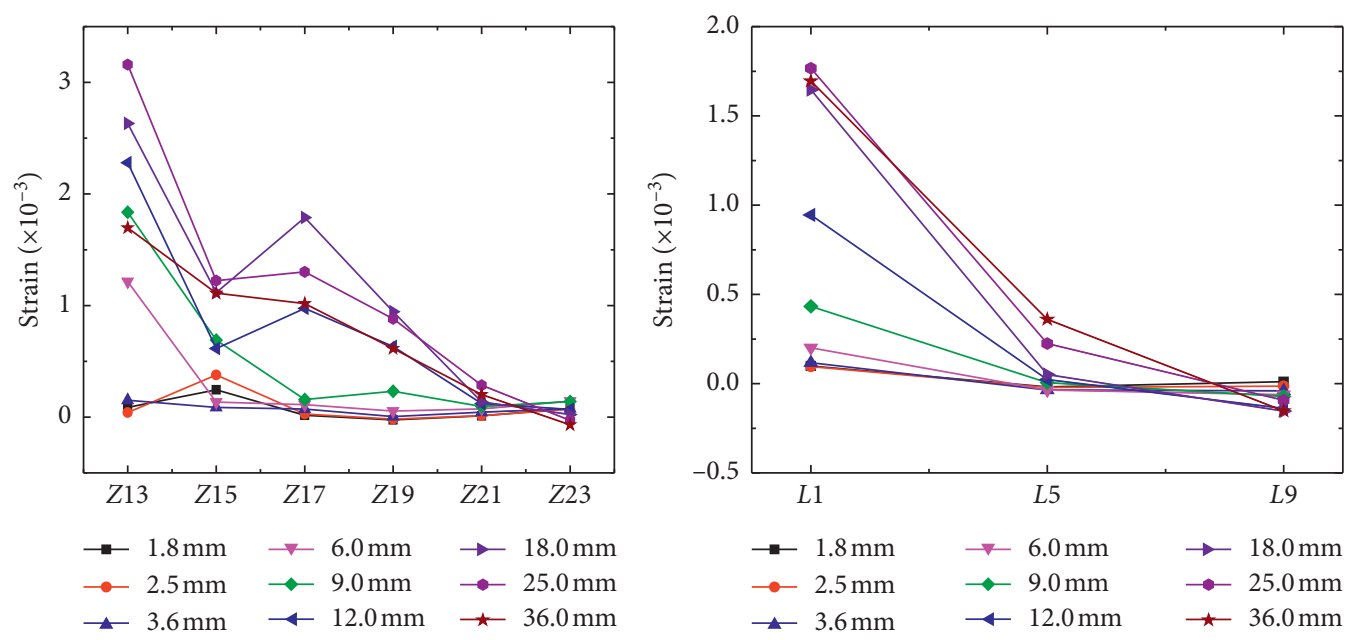

(g)

Figure 19: Steel strain curve. (a) Specimen KJ1. (b) Specimen KJ2. (c) Specimen KJ3. (d) Specimen ZHQ1. (e) Specimen ZHQ2. (f) Specimen ZHQ3. (g) Specimen ZHQ4.

column, and buckling steel bar. The cast-in-situ phosphogypsum in grids is broken, and the specimen is destroyed finally.

\section{Conclusions}

The main conclusions are summarized on the basis of cyclic pseudostatic seismic testing of the reinforced concrete grid frame and the cast-in-situ phosphogypsum-reinforced concrete grid frame composite wall, as follows:

(1) The failure mode of the reinforced concrete grid frame is mainly the concrete fracture at the beam-column joints, the buckling of the steel bars. The failure mode of the composite wall is mainly the cracks appearing in the beam-column joint region, the cracking of the phosphogypsum, and finally the concrete breaking at the beam-column joint, the buckling of the steel bar.

(2) Compared with the reinforced concrete grid frame, the hysteretic performance of the composite wall is significantly improved, and the enclosed area is larger and the energy consumption is higher.

(3) The addition of cast-in-situ phosphogypsum in the reinforced concrete grid frame can significantly improve the bearing capacity of the composite wall. Compared with the reinforced concrete grid frame, the ultimate bearing capacity of the composite wall is increased by at least $134.39 \%$, which means that the plastic deformation capacity of the reinforced concrete grid frame is effectively improved.

(4) The axial compression ratio has a great influence on the displacement ductility coefficient, limit displacement angle, and relative cumulative energy consumption of the composite wall.

(5) Compared with the reinforced concrete grid frame, the strength of the composite wall is relatively large. At the initial stage of loading, the stiffness decay speed is faster, but the destruction stiffness of the composite wall is still larger than the reinforced concrete grid frame.

\section{Notation}

d: $\quad$ Diameter

$f_{y}$ : Yield strength of steel bar

$f_{u}$ : Ultimate strength of steel bar

$E_{s}$ : Young's modulus of steel bar

n: $\quad$ Axial compression ratio

$N$ : Vertical load of specimen

$f_{c}$ : Compressive strength of concrete

$f_{p}$ : Compressive strength of phosphogypsum

$A_{c}$ : Cross-sectional area of column

$A_{p}$ : Cross-sectional area of phosphogypsum

$\delta: \quad$ Displacement of loading point

$\theta$ : Interlayer displacement angle

$F$ : Counterforce of loading point

$F_{\text {cr: }}$ Cracking load of specimen

$F_{y}: \quad$ Yield load of specimen

$F_{\text {max }}$ : Peak load of specimen

$F_{u}$ : Ultimate load of specimen

$\delta_{\mathrm{cr}}$ : Cracking displacement of specimen

$\delta_{y}$ : Yield displacement of specimen

$\delta_{\text {max }}$ : Peak displacement of specimen

$\delta_{u}$ : Ultimate displacement of specimen

$\mu$ : Displacement ductility coefficient

$\theta_{u}: \quad$ Limit displacement angle

$\phi$ : $\quad$ Reduction factor of bearing capacity

$h_{e}$ : Equivalent viscous damping coefficient

E: Accumulated energy consumption

$E_{r}: \quad$ Relative accumulated energy consumption

$K_{i}$ : $\quad$ Stiffness of the specimen in $i$ load cycles.

\section{Data Availability}

The data used to support the findings of this study are available from the corresponding author upon request. 


\section{Conflicts of Interest}

The authors declare that they have no conflicts of interest.

\section{Acknowledgments}

The authors would like to thank the National Natural Science Foundation of China (51168008) and the Guizhou Science and Technology Foundation ([2016]1040) and ([2019]1090), for financially supporting this research.

\section{References}

[1] T. T. Ye, J. P. Ding, and X. W. Zhu, "Phosphorus pollution prediction of no. 34 spring in Wujiang Town," Journal of Guizhou University (Natural Sciences), vol. 34, no. 3, pp. 115-120, 2017.

[2] Z. L. Sun, "Outlook and thinking of phosphogypsum comprehensive utilization in China," Sulphuric Acid Industry, vol. 1, pp. 55-58, 2016.

[3] J. Tian, Y. H. Yuan, Z. L. Huang et al., "Status and prospect of comprehensive utilization of phosphogypsum," The World of Building Materials, vol. 39, no. 4, pp. 38-40, 2018.

[4] J. J. James and P. K. Pandian, "Plasticity, swell-shrink, and microstructure of phosphogypsum admixed lime stabilized expansive soil," Advances in Civil Engineering, vol. 2016, Article ID 9798456, 10 pages, 2016.

[5] X. L. Xue, Y. X. Ke, Q. Kang et al., "Cost-effective treatment of hemihydrate phosphogypsum and phosphorous slag as cemented paste backfill material for underground mine," Advances in Materials Science and Engineering, vol. 2019, Article ID 9087538, 11 pages, 2019.

[6] G. M. S. Islam, F. H. Chowdhury, M. T. Raihan, S. K. S. Amit, and M. R. Islam, "Effect of phosphogypsum on the properties of Portland cement," Procedia Engineering, vol. 171, pp. 744-751, 2017.

[7] X. W. Jia, Z. Wu, and Y. Ma, "Present status of phosphogypsum utilization in building material," Materials Reports, vol. 27, no. 23, pp. 139-141, 2013.

[8] D. Nizevičienè, D. Vaičiukynienè, B. Michalik, M. Bonczyk, V. Vaitkevičius, and V. Jusas, "The treatment of phosphogypsum with zeolite to use it in binding material," Construction and Building Materials, vol. 180, pp. 134-142, 2018.

[9] W. Xiao, X. Yao, and F. Y. Zhang, "Recycling of oily sludge as a roadbed material utilizing phosphogypsum-based cementitious materials," Advances in Civil Engineering, vol. 2019, Article ID 6280715, 10 pages, 2019.

[10] Z. Gu, S. D. Hua, W. X. Zhao, S. S. Li, Z. Gao, and H. T. Shan, "Using alkali-activated cementitious materials to solidify high organic matter content dredged sludge as roadbed material," Advances in Civil Engineering, vol. 2018, Article ID 2152949, 10 pages, 2018.

[11] K. J. Ma, G. F. Gao, H. G. Zhang et al., "Research and application on space grid frame construction used in multi-story and tall buildings with energy saving and large bays," Spatial Structures, vol. 15, no. 3, pp. 65-84, 2009.

[12] J. X. Cao, L. Yang, Q. Lin et al., Research Report of Phosphorus Building Plaster Walls on Grouting Material and Field Construction, Guizhou University, Guiyang GZ 851 China, 2009.

[13] Q. Wu, H. G. Zhang, X. F. Jia et al., "Experimental investigation of stress-strain curves of cast-in-situ phosphogypsum," Journal of Building Structures, vol. 36, no. 5, pp. 150-157, 2015.
[14] H. G. Zhang, Q. Wu, X. F. Jia et al., "Experimental investigation on compressive strength of cast-in-situ phosphogypsum," Journal of Hunan University (Natural Sciences), vol. 43, no. 3, pp. 127-134, 2016.

[15] K. J. Ma, Y. Q. Lu, H. G. Zhang et al., "Experimental study on new type reinforced concrete structural system with phosphogypsum as a template," Journal of Building Structures, vol. 30, no. 6, pp. 128-133, 2009.

[16] H. G. Zhang, F. F. Liang, Y. Luo et al., "Energy-saving and structure integration of new-type wall structure based on castin-situ phosphogypsum and its application," Journal of Guizhou University (Natural Sciences), vol. 30, no. 1, pp. 104-110, 2013.

[17] H. G. Zhang, Q. Wu, L. L. Song et al., "Overall stability analysis of grid frame structure," Spatial Structures, vol. 21, no. 2, pp. 55-59, 2015.

[18] Y. Q. Lu, L. Hu, K. J. Ma et al., "Test research on the wall of new type RC grid frame structure," Journal of Hunan University (Natural Sciences), vol. 40, no. 4, pp. 8-14, 2013.

[19] X. L. Jiang, K. Liu, Y. Gu et al., "Experimental research on behavior of closely spaced concrete frames-fiber reinforced plasterboard under low cyclic loading," Journal of Building Structures, vol. 25, no. 4, pp. 50-54, 2004.

[20] X. L. Jiang, L. F. Xin, N. Jiang et al., "Experimental research on heat-reservation fiber-plasterboard wall reinforced with infilled RC columns under low cyclic loading," Industrial Construction, vol. 45, no. 12, pp. 104-109, 2015.

[21] GB50010-2010, Design Code of Concrete Buildings, China Architecture \& Building Press, Beijing, China, 2010.

[22] JGJ/T101-2015, Specification of Testing Methods for Earthquake Resistant Building, China Architecture \& Building Press, Beijing, China, 2015.

[23] J. R. Tang, Seismic Resistance of Joints in Reinforced Concrete Frames, Nanjing: Southeast University Press, Nanjing, China, 1989.

[24] Z. K. Shen, New Standard Test Method for Application Evaluation of Concrete Structure, Beijing: Seismological Press, Beijing, China, 1992.

[25] M. R. Song, J. X. He, Y. Liu et al., "Seismic behaviour of threestory prestressed fabricated concrete frame under dynamic and low reversed cyclic loading," Advances in Civil Engineering, vol. 2018, Article ID 7876908, 10 pages, 2018.

[26] J.-B. Gu, Y. Tao, R. Xin, Z. Yang, and Q.-X. Shi, "Seismic performance of multi-storey masonry structure with openings repaired with CFRP grid," Advances in Civil Engineering, vol. 2018, Article ID 4374876, 11 pages, 2018. 


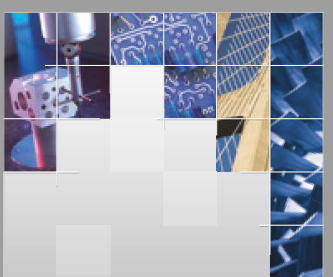

\section{Enfincering}
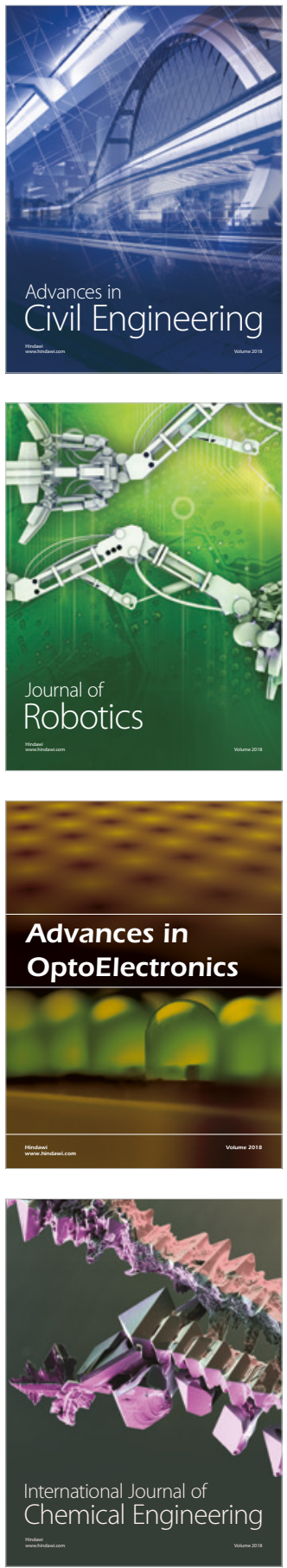

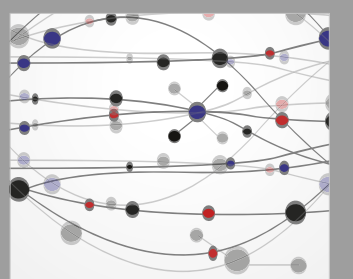

\section{Rotating \\ Machinery}

The Scientific World Journal

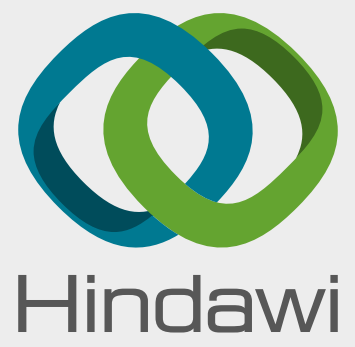

Submit your manuscripts at

www.hindawi.com
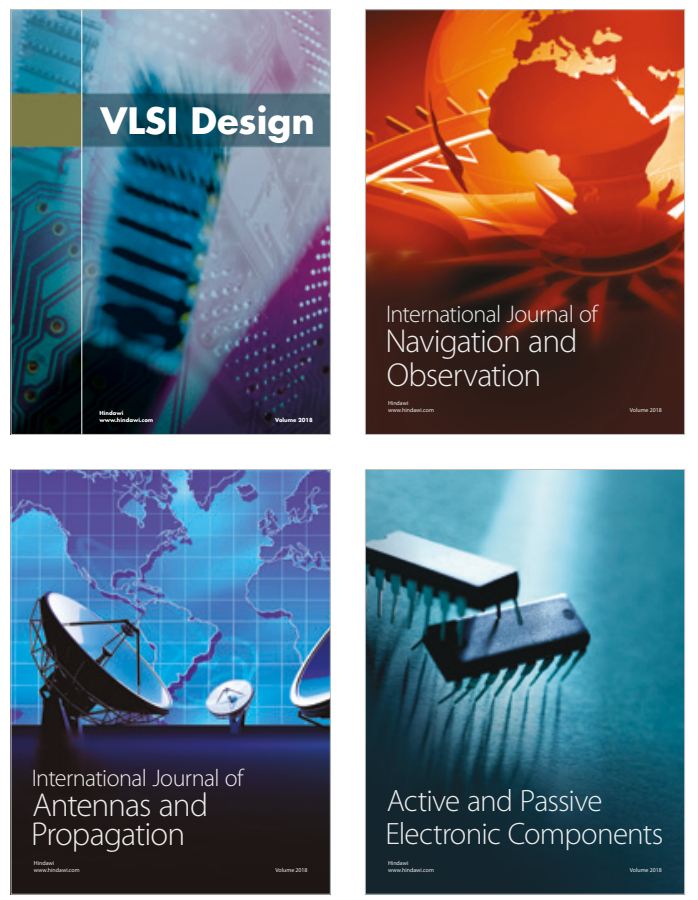
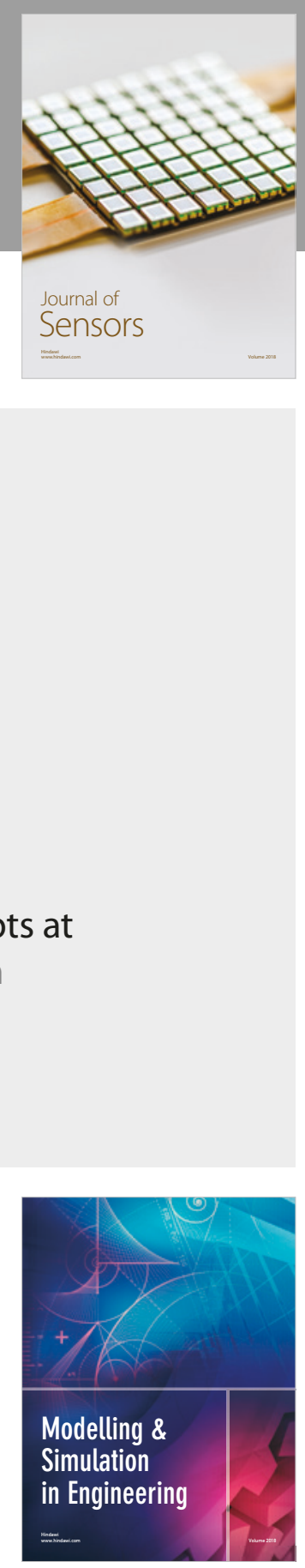

\section{Advances \\ Multimedia}
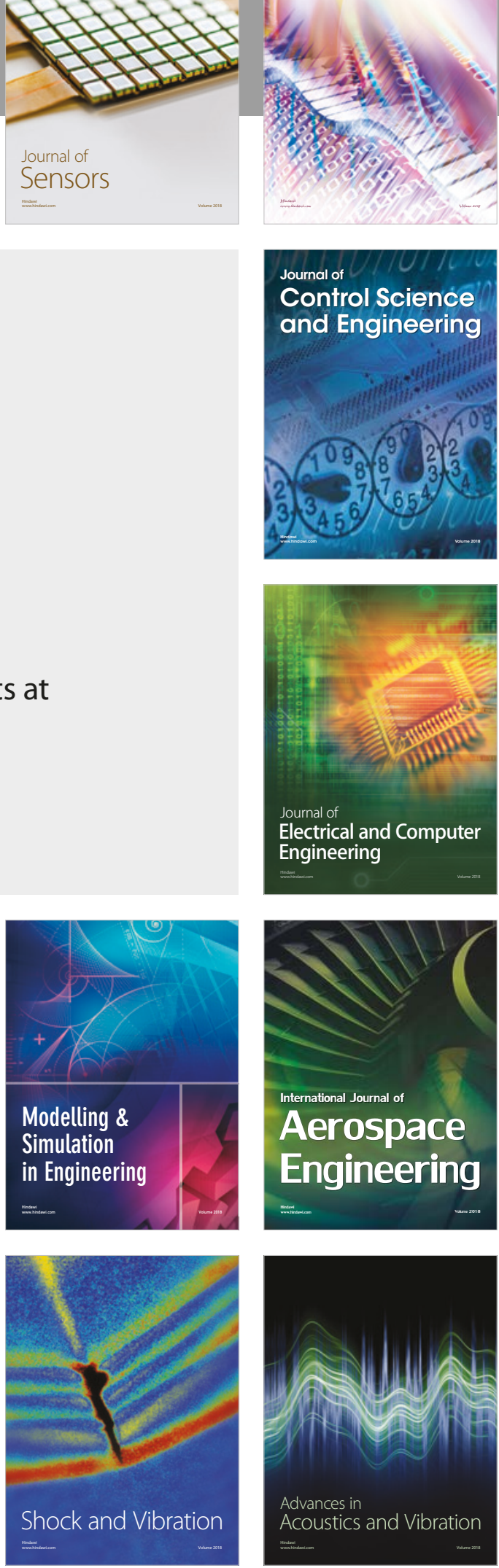